\title{
Um Modelo Evolucionário de Busca Tecnológica em Condições de Hipercumulatividade*
}

\author{
Sergio Almeida de Sousa**
}

Sumário: 1. Introdução; 2. O modelo de busca tecnológica; 3. Dinâmica industrial em condições de hipercumulatividade tecnológica: simulações do modelo PK revisitado; 4. Conclusões.

Palavras-chave: concorrência e inovação; dinâmica industrial; spillovers de P\&D; modelo evolucionário de inovação e imitação.

Códigos JEL: O32; L25; B52; C63.

Entre os vários modelos que Nelson e Winter (1982) propuseram, o de concorrência com progresso técnico endógeno foi o que mais se difundiu e forneceu insights sobre a relação entre mudança tecnológica e a estrutura de mercado. Embora os modelos evolucionários de dinâmica industrial desenvolvidos nas duas décadas seguintes tenham feito uma série de avanços, persistem nos modelos dessa corrente algumas limitações do modelo Nelson-Winter ligadas ao processo de busca tecnológica. O objetivo do artigo é elaborar um modelo de busca tecnológica com características (cumulatividade tecnológica, spillovers de P\&D assimétricos e acumulação de conhecimento com depreciaç ão intertemporal) capazes de superar aquelas limitações.

One of the most influential evolutionary models in Nelson and Winter's book is the one dealing with industrial dynamics. From that model came out meaningful insights about market structure and technological change relationship. Despite the improvements made by evolutionary models that have arisen since Nelson and Winter's book, this stream of models still shares some of the original limitations from Nelson and Winter's model. All of those limitations are related to the technological search part of the model. Thus, this article aims to build a new technological search model with properties (technological cumulativeness, asymmetrical R\&D spillovers and knowledge accumulation and intertemporal depreciation) that are capable to solve those limitations.

${ }^{*}$ Artigo recebido em jul. 2004 e aprovado em mar. 2005. Agradeço a Mario Possas, Paulo Fernando, Antônio Licha, Jorge Brito e Marcelo Resende pelas sugestões e comentários valiosos e a Esther Dweck pela assistência nas simulações. Agradeço ainda a Ana Cristina pela revisão do texto. Os erros são meus.

** Universidade de Notitngham. E-mail: lexss12@nottingham.ac.uk 


\section{Introdução}

Alterações na modelagem do processo de busca (search) tecnológica nos modelos evolucionários de concorrência têm a capacidade de modificar crucialmente os resultados colecionados pelos modelos desenvolvidos nas últimas duas décadas. É através da busca tecnológica que as firmas, seja por imitação, seja por inovação, introduzem novas técnicas no intuito de manter ou obter melhor desempenho no processo competitivo. Assim, a busca tecnológica representa a parte dos modelos de competição que lida com a formalização dos aspectos internos e externos à indústria ligados ao progresso técnico da firma.

Mas a importância econômica atribuída à mudança técnica não é exclusiva do enfoque evolucionário. Embora o interesse analítico pela questão do progresso técnico na literatura mainstream tivesse como propósito mais geral retomar os estudos sobre Economia do Desenvolvimento na perspectiva de superar a exogeneidade dos resultados dos modelos de crescimento à la Solow (Nelson, 1995, Possas, 1999), a freqüência com que a questão tem aparecido nos aportes teóricos mais recentes para a literatura de crescimento econômico (e.g. Romer (1994); Aghion e Howitt (1992); Grossman e Helpman (1994), Aghion et alii (1991)) sugere uma consolidação da mudança tecnológica como fonte de crescimento e mudança estrutural na economia.

Entretanto, antes dessas incursões mais recentes no tema, Nelson e Winter (1975, 1977, 1982) já haviam tentado, sob influência dos trabalhos de Schumpeter associando as inovações às oscilações cíclicas no ritmo de atividade da economia, destacar a dimensão tecnológica dos processos de competição nos mercados. Entre os vários modelos que propuseram, o de dinâmica industrial com progresso técnico endógeno (Nelson e Winter (1982); doravante NW) foi o que mais se difundiu e forneceu insights importantes sobre a relação entre o processo de mudança tecnológica e a estrutura de mercado. Uma versão modificada do modelo (Winter, 1984) explora novas fontes de mudança técnica (entrada de novas firmas) e introduz feedbacks entre as estratégias e o desempenho da firma que conferem flexibilidade aos processos decisórios ligados à política de $\mathrm{P} \& \mathrm{D}$. A partir daí surgiram outros modelos $^{1}$ (Silverberg et alii, 1988, Chiaromonte e Dosi, 1993, Kwasnicki, 1996,

\footnotetext{
${ }^{1}$ Há outros modelos de dinâmica industrial - Jovanovic (1982), Hopenhayn (1992) e Ericson e Pakes (1995) - que pretendem conciliar uma perspectiva "evolucionária" com uma abordagem equilibrista, no que acabam por compartilhar de hipóteses - expectativas racionais, racionalidade substantiva, firma representativa, etc. - que os distanciam significativamente dos modelos da corrente neo-schumpeteriana que serão tratados aqui. Aliás, uma inconsistência analítica relativamente grave no trabalho de Ericson e Pakes (1995) foi formalmente apontada por Kaniovski (1998).
} 
Jonard e Yildizoglu, 1998, Winter et alii, 2000, Possas et alii, 2001) que, se por um lado - até por compartilhar das noções teóricas mais fundamentais ali presentes - reforçam e reutilizam a estrutura modelística original daqueles autores, por outro procuram remover suas simplificações mais evidentes e ampliar seu escopo de análise. ${ }^{2}$

A singularidade teórica desses modelos reside, basicamente, em três aspectos: (1) a ruptura com os modelos tradicionais de competição oligopolista que têm nas estratégias de preço, ou nas estratégias de (regulação de) oferta, a dimensão exclusiva da concorrência; (2) a tentativa de ilustrar a complementaridade das características tecnológicas e comportamentais da firma em determinar sua competitividade, parâmetro seletivo que sintetiza uma combinação das características operacionais e técnicas das firmas (e/ou de seus produtos); (3) a ênfase nas implicações de a dinâmica da indústria poder estar condicionada, de modos diferentes, a características "dependentes de trajetórias" (path-dependent) ou inerciais das firmas.

Não obstante os avanços que tais modelos fizeram, é possível apontar algumas limitações herdadas do modelo Nelson-Winter ligadas ao processo de busca tecnológica. Como veremos mais adiante, tais limitações são cruciais não apenas porque, à luz das evidências existentes na literatura empírica ligada ao tema, empobrecem a descrição analítica dos processos que promovem a mudança técnica nas indústrias, mas porque, uma vez superadas, podem promover mudanças significativas nos resultados colecionados por uma série de modelos de dinâmica industrial elaborados ao longo de duas décadas, desde a publicação do livro (Nelson e Winter, 1982) que marca o surgimento formal desse tipo de literatura. ${ }^{3}$

Assim, o objetivo deste artigo é desenvolver um modelo de busca tecnológica (inovação/imitação) onde: (1) as firmas acumulam conhecimento, cuja depreciação pode ser de natureza cognitiva ou tecnológica, (2) existem spillovers (externalidades positivas) assimétricos de P\&D, (3) há cumulatividade tecnológica - realimentação dos processos estocásticos que definem o sucesso da busca tecnológica -, e (4) há endogenização das trajetórias tecnológicas das firmas. Com tais aspectos, o modelo pretende superar limitações do processo de busca tecnológica de uma série de modelos evolucionários de dinâmica industrial e, incorporando tais mudanças ao modelo de dinâmica industrial proposto por Possas et alii (2001),

\footnotetext{
${ }^{2}$ Mais detalhes, Almeida (2004).

${ }^{3}$ Está além do escopo desse trabalho discutir as semelhanças do enfoque evolucionário aqui utilizado com a literatura evolucionária em teoria dos jogos que, a rigor, também surgiu na década de oitenta a partir dos trabalhos de Maynard-Smith (1982) e Axelrod (1984). Digo a rigor porque ambos os enfoques se privilegiaram de trabalhos "evolucionários" elaborados, respectivamente, na década de 50 (Alchian) e 60 (Lewontin).
} 
avaliar o impacto dessas mudanças no desempenho intertemporal das firmas e no próprio grau de concentração da indústria.

O artigo conterá mais três seções além desta introdução. Na próxima seção será apresentado o modelo de busca tecnológica. A fim de avaliar as implicações dos novos aspectos integrados ao processo de mudança técnica sobre a trajetória intertemporal de certas variáveis da indústria, integraremos o processo de busca tecnológica desenvolvido ao modelo proposto por Possas et alii (2001). ${ }^{4}$ Assim, na terceira seção serão feitas algumas simulações da dinâmica de uma indústria sob as duas especificações do processo de busca tecnológica. Por fim, serão apresentadas as conclusões.

\section{O Modelo de Busca Tecnológica}

\subsection{Considerações preliminares}

O modelo apresentado a seguir pode ser visto como uma série de especificações analíticas que buscam representar o processo de mudança técnica (seja por meio de inovação, seja por imitação) em um setor industrial. Esse processo, embora também esteja ligado ao acúmulo de conhecimento e capacitações tecnológicas, está baseado, essencialmente, nos esforços de P\&D da firma. A busca tecnológica, em que pese tratar-se de um dos principais "módulos" dos modelos evolucionários, refere-se apenas a parte do conjunto de decisões e aspectos da dinâmica das firmas. Assim, o modelo aqui desenvolvido não possui uma dinâmica própria sem que seja coligado a outros elementos do processo competitivo (formação de preços, produção, etc.), já que o esforço de $\mathrm{P} \& \mathrm{D}$ da firma depende de outras variáveis (receita de vendas, preço, etc.) determinadas no âmbito das decisões de produção e pelas próprias condições iniciais de demanda do mercado; nesse sentido, o modelo

\footnotetext{
${ }^{4}$ Dentro da literatura evolucionária, o modelo escolhido é relativamente completo; primeiro, porque fundiu características de outros dois modelos evolucionários (o tratamento do processo de mudança tecnológica presente no modelo Nelson-Winter e o efeito do aprendizado do tipo by doing presente no modelo proposto por Silverberg et alii (1988)) cujas especificações não mais reproduzem certas limitações originais do modelo NW; segundo, porque, diferentemente de seus antecessores, (1) adiciona alguns elementos de inspiração Keynesiana para formalizar a influência da demanda nas decisões de produção, e (2) incorpora mecanismos de retroalimentação na formação de preço das firmas que conferem maior adaptabilidade às condições de mercado. Doravante nos referiremos a este modelo como PK.
} 
proposto pode ser integrado a qualquer um dos modelos evolucionários que seguem a estrutura do processo de busca tecnológica do modelo Nelson-Winter, o que só não é possível pela generalidade com que é formulado mas necessário para que suas implicações sejam derivadas.

\subsection{Estrutura do modelo: descrição e motivações}

A descrição do modelo proposto passa por três etapas:

- a definição dos elementos que conformam o estoque ou a base de conhecimento das firmas, aí introduzindo, como proposto, os spillovers de P\&D;

- a reformulação do processo probabilístico que indica o sucesso ou fracasso das estratégias tecnológicas da firma, introduzindo o efeito que o histórico tecnológico da firma pode ter sobre o resultado das estratégias no período corrente; e

- a endogeneização do processo de mudança técnica das firmas bem-sucedidas em suas estratégias (inovação ou imitação) em direção à fronteira tecnológica. As trajetórias tecnológicas das firmas (direção e velocidade do progresso técnico) dependerão do conhecimento e da competência tecnológica (um indicador de eficiência) que possuem. Tais trajetórias apresentarão fases distintas que podem ser percorridas diferentemente. Esses aspectos tornarão o processo de mudança técnica mais geral do que o caso exógeno prevalecente no modelo Nelson-Winter.

A fim de que fique claro como tais elementos serão articulados e em que sentido resolverão as limitações apontadas do modelo Nelson-Winter, convém fazer alusão, com um pouco mais de detalhe, para as justificativas de cada uma dessas etapas.

Quanto à primeira etapa, a base de conhecimento que cada firma detém representa uma articulação intertemporal (a) do conhecimento que deriva de seu próprio esforço tecnológico (traduzido em seu gasto em $\mathrm{P} \& \mathrm{D}$ ), e (b) dos spillovers de $\mathrm{P} \& \mathrm{D}$ (intra-industriais e aquele levado a cabo por instituições públicas de pesquisa) efetivamente apropriados, o que depende da capacidade de absorção detida. Contudo, a incidência de um processo intertemporal de depreciação sobre o estoque de conhecimento da firma impede que todo o conhecimento e toda a capacitação tecnológica acumulados pelas firmas sejam exploráveis a cada período.

A idéia de depreciação da base de conhecimento utilizada pela firma está presente em alguns modelos de dinâmica industrial (Silverberg e Verspagen, 1994, 
Llerena e Oltra, 2000), mas claramente como uma analogia com o tipo de depreciação que opera sobre ativos produtivos. Esse tipo de depreciação diz respeito ao desgaste físico dos ativos, logo, está associado à intensidade de sua utilização. Há duas razões lógicas para rejeitar esse tipo de formulação simplificada. Em primeiro lugar, porque a deterioração de parte do conhecimento acumulado não poderia estar associada à intensidade com que esse conhecimento é usado, já que ele não é exaurível à medida que é utilizado, mas sim com algum grau de interferência (ainda que dentro de um mesmo paradigma tecnológico) que o acúmulo de novos conhecimentos e competências, e até mesmo o fracasso de suas estratégias tecnológicas, pode provocar na utilização de módulos (ou partes) da base de conhecimento acumulado incorporados em um período relativamente longínquo. Em segundo, porque sua incidência não poderia ser homogênea, já que a base de conhecimento explorável em um período $t$ representa uma composição que articula tipos distintos de conhecimento (tácito e codificado), internalizados em diferentes períodos e fases tecnológicas e cujo grau de codificação é intertemporalmente variável e específico a cada firma. ${ }^{5}$ A idéia a ser desenvolvida em seguida é a de que o conhecimento acumulado a ser explorado a cada período tem uma composição que tende a privilegiar, proporcionalmente, os módulos mais recentemente adquiridos, seja por uma adequação maior à atual fase tecnológica em que se encontra, seja por limitações cognitivas na evocação do conhecimento inscrito nas rotinas de busca tecnológica realizadas anteriormente.

Quanto à segunda etapa, ao colocar a base de conhecimento e capacitações tecnológicas da firma como argumento do processo estocástico que define o resultado da busca tecnológica, permite-se que a influência do esforço passado de P\&D sobre seu ritmo de progresso técnico seja contínua. Além disso, será introduzida cumulatividade tecnológica: um processo de realimentação da busca tecnológica que deriva exclusivamente do sucesso inovativo ou imitativo alcançado pela firma em períodos prévios. Ambos os aspectos são considerados fatos estilizados sobre o processo de P\&D (Adams (2000), Malerba e Orsenigo (1997), Kay (1988), Dosi (1988)).

Vejamos mais de perto como os dois aspectos, logo acima referidos, resolvem limitações relevantes nos modelos evolucionários referidos acima. Há dois problemas internos no processo de busca tecnológica à la Nelson-Winter. De um lado,

\footnotetext{
${ }^{5}$ Com algumas simplificações e esforço interpretativo, essa taxa de depreciação única que incide sobre o estoque de conhecimento poderia ser vista como uma média que condensaria, de forma aproximativa, a depreciação de natureza cognitiva (sobre a parte tácita) e de natureza tecnológica (sobre a parte codificada) que está sendo proposta. Ainda assim, isso pode produzir vieses nos resultados porque não capta assimetrias importantes na composição do conhecimento e das capacitações acumulados que a firma explora.
} 
o esgotamento instantâneo dos efeitos do esforço de $\mathrm{P} \& \mathrm{D}$ no período em que são realizados. Isto é, o esforço de $\mathrm{P} \& \mathrm{D}$ realizado no período $t-i$ não exerce efeito direto sobre as chances de sucesso tecnológico no período $t$, qualquer que seja o valor inteiro positivo de $i$. Segue logicamente daí que o progresso técnico da firma num período $t$ qualquer depende exclusivamente do esforço de $\mathrm{P} \& \mathrm{D}$ realizado naquele período. É evidente que essa formulação implica a existência de uma espécie de descontinuidade contínua incompatível com a natureza cumulativa da atividade de P\&D. De outro lado, a inexistência de um mecanismo formal de realimentação estritamente tecnológico. Embora exista uma realimentação positiva do potencial inovativo ou imitativo da firma, ela não é tecnológica, isto é, ela não é diretamente derivada do sucesso tecnológico prévio, mas sim uma realimentação repleta de mediações que a tornam, ao fim de tudo, muito mais próxima a uma espécie de efeito tamanho. $^{6}$

Desse modo, a presença de uma variável de estoque e de um mecanismo de realimentação baseado em desempenho cria duas fontes de cumulatividade que podem ser combinadas para criar uma tipificação da dinâmica industrial sob diferentes regimes tecnológicos (Malerba e Orsenigo, 1997): um em que há apenas cumulatividade normal (relativa apenas aos efeitos do maior esforço de P\&D sobre a base de conhecimento e capacitações tecnológicas que a firma possui) e outro em que existe hipercumulatividade (os elementos da cumulatividade normal combinados com as vantagens ligadas ao desempenho tecnológico prévio da firma - de sucesso ou fracasso).

Por fim, quanto à terceira etapa, a formulação da base de conhecimento e de capacitações tecnológicas da firma servirá ainda para a endogeneização do ritmo e direção com que a firma explorará as oportunidades tecnológicas - um espectro de níveis de produtividade existentes entre os estágios inicias e a fronteira tecnológica da indústria, ambos determinados pelo paradigma tecnológico prevalecente. A endogeneização da trajetória tecnológica das firmas objetiva eliminar as implicações que a exogeneidade da taxa de crescimento das oportunidades tecnológicas tem sobre o padrão evolutivo da fronteira de produtividade das firmas. ${ }^{7}$ De fato, o

\footnotetext{
${ }^{6}$ Como, aliás, parece sugerir Coombs (1988:299) e está explicitado em artigo anterior (Veja Nelson e Winter (1977); ou, ainda, se trata apenas de um market feedback. Essa aparente cumulatividade tecnológica do modelo $\mathrm{NW}$, não bastasse derivar em grande parte da rigidez das estratégias de P\&D (Almeida, 2004), tem por trás um ciclo de mediações que, embora não seja instantâneo, possui um timing provavelmente mais longo e carregado de condicionantes do que aquele presente no mecanismo de realimentação aqui proposto, de natureza tecnológica - e que não exclui ou invalida aquele.

${ }^{7}$ Logo, também sobre o grau de concentração da indústria. Ver a respeito, por exemplo, Possas et alii (2001).
} 
problema não está especificamente na exogeneidade do ritmo de crescimento da fronteira tecnológica, mas na inexistência de um processo de exploração das oportunidades tecnológicas ${ }^{8}$ que evite que a exogeneidade da fronteira transmita-se diretamente para a própria trajetória tecnológica da firma.

\section{Base de conhecimento e capacitações tecnológicas da firma}

Seja $\Gamma_{i, t}$ a base de conhecimento tecnológico explorável da firma $i$ no período $t$, formada (1) pelo conhecimento tecnológico acumulado previamente que está efetivamente disponível no período $t, \widetilde{\Gamma}_{i, t},(2)$ pelo conhecimento tecnológico associado ao próprio esforço de $\mathrm{P} \& \mathrm{D}$ que a firma realiza no período corrente, $E_{i, t},(3)$ pelo conhecimento que "transborda" da atividade de P\&D das firmas rivais (spillovers intra-industriais), $S_{i, t}$, e (4) por aquele outro tipo de conhecimento externo à firma, proveniente, com adequação maior ou menor às necessidades tecnológicas da firma, do sistema público de pesquisa (laboratórios, órgãos de pesquisa e o próprio sistema universitário) e da atividade de $\mathrm{P} \& \mathrm{D}$ realizada em outros setores e que será aqui representado por $S_{t}^{P}$.

Certamente a expressão da base de conhecimento tecnológico da firma apenas com esses elementos estaria incompleta. É preciso estabelecer ainda que a capacidade de a firma assimilar, e converter às suas necessidades, o conhecimento tecnológico que "vaza" da própria atividade de $\mathrm{P} \& \mathrm{D}$ das firmas rivais ou que é exógeno ao setor e de domínio público, depende da capacidade de absorção $\left(0 \leq \xi_{i, t} \leq 1\right)$ que possui. Tal capacidade é aprimorada pelo esforço de $\mathrm{P} \& \mathrm{D}$ contínuo que realiza - donde segue que o esforço de $\mathrm{P} \& \mathrm{D}$, para além de seus efeitos sobre a geração de conhecimento/inovações, possui um papel dual na atividade tecnológica da firma, como demonstrado por Cohen e Levinthal (1989).

Assim, a base de conhecimento e das capacitações tecnológicas da firma pode ser definida como 9

$$
\Gamma_{i, t}=\widetilde{\Gamma}_{i, t}+E_{i, t}+\xi_{i, t}\left(S_{i, t}+S_{t}^{P}\right)
$$

sabendo-se que a relação entre $\Gamma_{i}$ e cada um dos elementos do lado direito da equação acima é tal que

\footnotetext{
${ }^{8}$ Com a expressão "exploração das oportunidades tecnológicas" quero referir-me ao processo (intertemporal) de transição entre o nível de produtividade da melhor tecnologia de que a firma dispõe no período $t$ e o nível de produtividade (superior) da fronteira tecnológica da indústria que a firma (inovativa) acessa quando bem-sucedida em seu esforço de P\&D. Mutatis mutandi, o mesmo vale para as firmas imitadoras.

${ }^{9} \mathrm{~A}$ idéia de um estoque de conhecimento que se expande a partir dos gastos correntes em P\&D e da absorção de spillovers de P\&D está baseada no trabalho de Cohen e Levinthal (1989).
} 


$$
\Gamma_{E_{i}}^{\prime}>0, \Gamma_{S_{i}}^{\prime}>0, \Gamma_{S^{P}}^{\prime}>0, \Gamma_{\xi_{i}}^{\prime}>0
$$

notando-se ainda que o efeito da capacidade de absorção sobre a base de conhecimento acumulada cresce a taxas decrescentes, isto é, $\Gamma_{\xi_{i} \xi_{i}}^{\prime \prime}<0$. Como $\widetilde{\Gamma}_{i, t}$, representa o conhecimento previamente acumulado que está disponível em $t$ (ou seja, já devidamente "depreciado"), a partir de (1) tem-se então que, em tempo discreto,

$$
\Delta \Gamma_{i, t}=E_{i, t}+\xi_{i, t}\left(S_{i, t}+S_{t}^{P}\right)-\tilde{d}_{i, t}^{\Gamma}
$$

significando que, entre o período $t$ e $t-1$, o conhecimento tecnológico associado ao esforço interno de $\mathrm{P} \& \mathrm{D}$ e aos spillovers intra e extra-industriais efetivamente internalizados adicionam-se ao "estoque" prévio existente; todavia, deve-se subtrair a parte $\tilde{d}_{i, t}^{\Gamma}$ do conhecimento acumulado previamente que foi "depreciada"; $\tilde{d}_{i, t}^{\Gamma}$, como será visto em seguida, é uma medida da perda total pela qual passa a base de conhecimento da firma; contudo, o tipo de depreciação que incide sobre o conhecimento acumulado depende da estrutura atual de organização do conhecimento dentro da firma, entre o que é tácito e o que é codificado - distinção, de resto, já apontada em Nelson e Winter (1982) e explorada mais detalhadamente em Dosi (1996), Zack (1999), Balconi (2000), Grimaldi e Torrisi (2001) e Antonelli (2002).

Assim, o termo $\tilde{d}_{i, t}^{\Gamma}$ na equação (2), em notação vetorial, pode ser decomposto da seguinte forma:

$$
\widetilde{\mathbf{d}}_{i, t}^{\Gamma}=\left(\mathbf{1}^{\prime}-\mathbf{D}_{T(i)}^{\prime}\right)\left(1-\eta_{i, t}\right) \widehat{\boldsymbol{\Gamma}}^{\Delta(i, t-1)}+\left(\mathbf{1}^{\prime}-\mathbf{D}_{C(i)}^{\prime}\right) \eta_{i, t} \widehat{\boldsymbol{\Gamma}}^{\Delta(i, t-1)}
$$

onde $\mathbf{D}_{T(i)}^{\prime}=\left[\rho_{1, k}^{T(i)}\right] ; k=1,2, \ldots, t-1$ e $\mathbf{D}_{C(i)}^{\prime}=\left[\rho_{1, k}^{T(i)}\right] ; k=1,2, \ldots, t-1$, são vetores-linha $\left(\in \mathcal{R}^{t-1}\right)$ cujos elementos determinarão, respectivamente, a taxa de depreciação da parte tácita $\left(\mathbf{1}^{\prime}-\mathbf{D}_{T(i)}^{\prime}\right)$ e a taxa de depreciação da parte codificada $\left(\mathbf{1}^{\prime}-\mathbf{D}_{C(i)}^{\prime}\right)$ do "módulo" de conhecimento incorporado no período $k$ à base de conhecimento da firma $i$; observe-se ainda que

$$
\widehat{\boldsymbol{\Gamma}}^{\Delta(i, t-1)}=\left[\Delta \widehat{\Gamma}_{k}^{i}\right] ; k=1,2, \ldots, t-1
$$


é um vetor-coluna $\left(\in \mathcal{R}^{t-1}\right)$ cujos elementos, $\Delta \Gamma_{k, 1}^{i}$, representam as várias "partes" que formam a base de conhecimento tecnológico da firma $i$ no período $t$ e que foram incorporadas no período $k$; a partir de (2), sabe-se que

$$
\Delta \widehat{\Gamma}_{k, 1}^{i}=E_{i, k}+\xi_{i, k}\left(S_{i, k}+S_{i, k}^{P}\right) ; k=1,2, \ldots, t-1
$$

Observe que a multiplicação do vetor $\widehat{\boldsymbol{\Gamma}}^{\Delta(i, t-1)}$ por um escalar $\left(\eta_{i, t}\right)$ que denota o grau de codificação da base de conhecimento tecnológico da firma no período $t$ - e, residualmente $\left(1-\eta_{i, t}\right)$, seu grau de taciticidade (tacitness) - garantirá que a incidência de cada taxa se dê apenas na parte que lhe corresponde. Das expressões em (3) e (5) podemos explicitar o componente $\widetilde{\Gamma}_{i, t}$ de (1):

$$
\widetilde{\Gamma}_{i, t}=\sum_{k=1}^{t-1} \eta_{i, t} \rho_{i, k}^{C} \Delta \widehat{\Gamma}_{k, 1}^{i}+\sum_{k=1}^{t-1}\left(1-\eta_{i, t}\right) \rho_{i, k}^{T} \Delta \widehat{\Gamma}_{k, 1}^{i}
$$

Resta agora apresentar os elementos dos vetores $\mathbf{D}_{C(i)}^{\prime}$ e $\mathbf{D}_{T(i)}^{\prime}\left(\rho_{i, k}^{C}\right.$ e $\left.\rho_{i, k}^{T}\right)$, indicadores indiretos do grau de "depreciação" intertemporal da base de conhecimento tecnológico da firma e o processo endógeno de codificação da base de conhecimento que determina os valores que $\eta_{i, t}$ pode assumir.

\section{Conhecimento tácito: a "depreciação" de natureza cognitiva}

Reconhecida as especificidades quanto ao tipo de armazenamento e organização do conhecimento tácito, disposto na memória dos indivíduos que conformam a organização interna da firma (por exemplo, Simon (1979) e Antonelli (2002)), é razoável postular que sua "depreciação" e, portanto, a especificação que será feita em seguida de $\rho_{i, k}^{T}$, envolve dois tipos de fenômenos cognitivos bem documentados na literatura psicológica. ${ }^{10}$

Primeiro, o fenômeno da interferência: o acúmulo de novos conhecimentos e os processos neuronais exigidos na sua articulação com o conjunto já acumulado de conhecimento tecnológico dariam origem a uma recombinação seletiva dos componentes tácitos da base de conhecimento da firma que tenderia a considerar primordialmente aquelas partes mais recentemente adquiridas em detrimento das relativamente mais antigas - que, de resto, estão associadas a outras fases da trajetória tecnológica da firma e mesmo a outros níveis de conhecimento acumulado. É como se o conhecimento tácito estivesse na "memória de trabalho" (com capa-

\footnotetext{
${ }^{10}$ A esse respeito veja-se Underwood (1957), Baddeley (1990) e Sternberg (1996).
} 
cidade de armazenamento limitada) ${ }^{11}$ cujo conteúdo seleciona proporcionalmente mais daquele conhecimento utilizado mais recentemente.

Segundo, o fenômeno da deterioração, que está associado a limitações cognitivas $^{12}$ na evocação de "partes" do conhecimento que foram integradas à base de conhecimento no passado remoto e recente. Os indivíduos que operam as rotinas operacionais e tecnológicas dentro da firma valem-se da própria memória como meio de recorrer ao conhecimento tácito do passado a fim de utilizá-lo no presente, e os mecanismos dinâmicos que governam os processos de armazenamento e recuperação da informação não impedem que alguma parte desse conhecimento seja perdida, basicamente porque as dificuldades na "ativação" desse conhecimento tácitas são tanto mais significativas quanto maior é o tempo decorrido.

Assim, tendo esses aspectos em mente, o passo seguinte é definir uma forma funcional para o elemento $\rho^{T}$ da equação em (6) que possua tais propriedades. Assim, a equação abaixo em (7) definirá a parte disponível (não "depreciada") do que é tácito em cada um dos "fluxos" de conhecimento incorporados à base $\Gamma$ da firma $i$ no período $t-k(k=1, \ldots, t-1)$ :

$$
\rho_{i, t-k}^{T}=\left(\frac{1}{k^{\delta}}\right)\left[1-r\left(\frac{\Gamma_{i, t-1}}{\Gamma_{i, t-k}}-1\right)\right]
$$

onde o primeiro e o segundo termos (entre colchetes) do lado direito da equação representam o efeito "deterioração" e o efeito "interferência", respectivamente; $\delta$ e $r$ são parâmetros - definidos tal que $\delta \in(0,1)$ e $r \in[0,1)$ - que indicam a velocidade de "depreciação" da parte tácita da base de conhecimento pelo "efeito deterioração" e o grau de interferência que o acúmulo de novos conhecimentos ${ }^{13}$

\footnotetext{
${ }^{11}$ Há por trás desse raciocínio um modelo de memória postulando que (1) o "armazenamento" do conhecimento é tanto mais consolidado (facilmente reutilizável) quanto maior é o seu grau de codificação, que (2) os indivíduos desempenham suas tarefas utilizando uma memória ("procedural", digamos) que integra elementos codificados contidos na "memória de longo prazo" que foram recentemente ativados com o conteúdo mais recentemente aprendido ainda não codificado. Existem, contudo, outros modelos de memória, mas essas proposições são compatíveis com as principais perspectivas, dentro da psicologia cognitiva, acerca do processo de organização da memória; veja-se, por exemplo, Baddeley (1990) e Sternberg (1996).

${ }^{12}$ McKelvey (1998), por exemplo, observa que "another interesting aspect is that displaying the ability to do something physical requires continuous practice to keep the tacit knowledge and reaction time at the top. Learning is thus based on doing as well as understanding, and tacit aspects of an activity can be forgotten even though the codified aspects are remembered"; similarmente, Dosi e Coriat (2002) notam que "organizational learning is obviously linked with the change of individual skills - sometimes indeed with the loss of some of them -, but also with changes of collective representations, rules, and even of hierarchical set-ups" (grifos nossos).

${ }^{13}$ Aqui inferidos pela taxa de crescimento da base de conhecimento da firma $i$ entre o período próximo passado $(t-1)$ e o período $(t-k)$ em que a parte que está sendo "depreciada" foi
} 
exerce sobre a proporção do conhecimento incorporado em $t-k$ que fará parte da composição corrente (atualizada) da base de conhecimento tecnológico da firma; observe-se a partir do exemplo seguinte que esses efeitos se reforçam.

Exemplo 1 Suponha-se que o conhecimento acumulado em $t-1$ fosse o dobro do que era em $t-k$ e que $r=0.01$; assim, conforme (5) e (7), a parte da base de conhecimento tecnológico da firma $i$ incorporada no período $t-k, \Delta \widehat{\Gamma}_{t-k}^{i}$, seria "depreciada" em 1\% para além do que seria apenas pelo efeito "deterioração". Logo, se a depreciação da parte tácita de $\Delta \widehat{\Gamma}_{t-k}^{i}$ pelo efeito "deterioração" fosse da ordem de $10 \%$, nesse caso, apenas $89 \%\left(1-\rho_{i t-k}\right)$ da parte tácita de $\widehat{\Gamma}_{t-k}$, por conta do "efeito interferência", estariam presentes na composição de $\widetilde{\Gamma}_{i, t}$, conforme fora definido em (6).

Corolário 1 A taxa intertemporal de "depreciação" $\left(1-\rho_{i, t-k}\right)$ da parcela tácita $d a$ base de conhecimento da firma $i$ no período $k$ possui duas propriedades. Primeiro, que a "depreciação" dos módulos mais "antigos" da base de conhecimento tecnológico da firma é relativamente maior, embora sua intensidade cresça a taxas decrescentes. ${ }^{14}$ Segundo, que a parte mais recentemente incorporada da base de conhecimento não sofre nenhum tipo de depreciação de natureza cognitiva.

Prova Para que $\left(1-\rho_{i, t-k}\right)$ tenha a primeira propriedade basta que a primeira e segunda derivada parcial (em relação a $k$ ) seja positiva e negativa, respectivamente. Então, fazendo $\chi=r\left(\frac{\Gamma_{i, t-1}}{\Gamma_{i, t-k}}-1\right)$, tem-se que

$$
\frac{\partial}{\partial K}\left(1-\rho_{i}^{T}\right)=\frac{\partial}{\partial K}\left[1-\left(\frac{1}{K^{\delta}}(1-\chi)\right]\right)=\frac{\delta}{K^{1+\delta}}(1-\chi)
$$

derivando novamente, vê-se que

$$
\frac{\partial^{2}}{\partial k^{2}}\left(1-\rho_{i}^{T}\right)=\frac{\partial}{\partial k}\left[\frac{\delta}{k^{1+\delta}}(1-\chi)\right]=-\frac{\delta(1+\delta)}{k^{2+\delta}}(1-\chi)
$$

donde segue, como se queria apontar, que:

incorporada à base de conhecimento da firma.

${ }^{14}$ A razão para não ser o contrário (a taxas crescentes) é simples: o conhecimento tácito associado às capacitações mais "antigas", ainda que esteja relativamente mais sujeito à "depreciação" vis à vis aquele associado às capacitações tecnológicas mais recentes, muito provavelmente possui um grau considerável de consolidação na base de conhecimento da firma. 


$$
\frac{\partial}{\partial k}\left(1-\rho_{i}^{T}\right)>0 \frac{\partial^{2}}{\partial k^{2}}\left(1-\rho_{i}^{T}\right)<0 . \text { A segunda propriedade vem de } \rho_{i, t-1}^{T}=1
$$

Observe-se ainda que o valor assumido por $\delta$ define um processo mais ou menos veloz de "depreciação" das partes da base de conhecimento menos recentemente incorporadas. Assim, supondo, sem perda de generalidade, um efeito "interferência" constante e fazendo, a partir da equação em $(11), D^{T}: \mathbb{N}^{*} \times(0,1) \rightarrow[0,1]$ (tal que $\left.D^{T}(k, \delta)=1-\rho_{i, t-k}\right)$ ser a função de "deterioração" do conhecimento tácito, temos que:

$$
\int_{a}^{b} D\left(k, \delta^{\prime}\right) d k>\int_{a}^{b} D\left(k, \delta^{\prime \prime}\right) d k \forall \delta^{\prime}>\delta^{\prime \prime}
$$

tal que

$$
k \in I_{n}=\{n \in \mathbb{N} ; n \leq t-1\} \text { e } \delta^{\prime}, \delta^{\prime \prime} \in(0,1)
$$

desde que $b>a>1$.

\section{Conhecimento codificado: a "depreciação" de natureza tecnológica}

A "depreciação" que pode incidir sobre o conhecimento codificado, ao contrário daquela associada ao conhecimento tácito, estaria muito mais ligada a mudanças na prática organizacional induzidas pela própria trajetória estratégica da firma mediadas pelo contexto tecnológico da firma e o "estado das artes" da ciência do que a alguma limitação de natureza cognitiva (Dosi e Coriat, 2002).

Nesse sentido, levantaremos dois elementos que justificariam a "depreciação" da parte codificada do conhecimento tecnológico. Primeiro, o desenvolvimento de novas pesquisas científicas (básica e/ou aplicada) cujos resultados podem impor alguma obsolescência ao conhecimento codificado prévio utilizado pela firma; não há dúvida que tal obsolescência será tanto mais elevada quanto maior for o grau de difusão das novas pesquisas - o que, em última instância, depende não apenas do grau de corroboração ${ }^{15}$ desses resultados e/ou do acúmulo de evidências falsificadoras do conhecimento prévio, mas do próprio surgimento de aplicações bem sucedidas, ainda que em estágio experimental.

\footnotetext{
${ }^{15}$ Que por si só afeta de modo adverso as expectativas tecnológicas (dos equipamentos em uso) das firmas - além de majorar os custos de oportunidade associados à compreensão de códigos e manuais que estão baseados em fundamentos teóricos e experimentos que dão indícios de desatualização.
} 
Segundo, e agora por uma razão específica à firma, porque ao fracassar na tentativa de gerar uma inovação/imitação que envolve a utilização de todo um conjunto de capacitações e conhecimento tecnológico previamente acumulados, a parte codificada desse conhecimento sofre uma revisão voluntária de modo a reorganizar e redefinir o conhecimento (ou parte) que será utilizado subseqüentemente; no entanto, a "depreciação" produzida por esse processo de rearticulação dos elementos codificados que formam a base de conhecimento da firma depende do sucesso prévio maior ou menor de suas estratégias tecnológicas. Trata-se de uma "depreciação" induzida pelo próprio histórico tecnológico da firma, que tende a ser tão mais intensa quanto maior são as evidências que a firma possui sobre a inadequação atual do conhecimento codificado já incorporado à base de conhecimento - obtidas a partir dos "fracassos" de suas estratégias tecnológicas no intervalo de tempo relevante.

Considerando, quanto ao primeiro motivo, que o progresso científico, em geral, é "normal" (e não "revolucionário") e não requer uma "depreciação", por obsolescência, além daquela imposta pela firma normalmente imporiam, é possível formalizar o elemento $\rho^{C}$ da equação em (6) tal que:

$$
\rho_{i, t-k}^{C}=\left(\frac{1}{(1+\alpha)}\right)^{\tilde{f}}
$$

indica a parte disponível (não "depreciada") do que é codificado em cada um dos "fluxos" de conhecimento que compõem a base da firma $i$ incorporados no período $t-k(k=1, \ldots, t-1)$. O parâmetro $\alpha(0<\alpha<<1)$ é um parâmetro que define o ritmo de "depreciação": para um mesmo $\tilde{f}$ (definido logo em seguida), a proporção do conhecimento codificado de certa parte da base de conhecimento a ser "depreciada" será tanto maior quanto maior for $\alpha$; trata-se de um sinalização da importância que a firma concede ao seu "histórico" tecnológico enquanto fonte básica de indicação da apropriabilidade maior ou menor do conhecimento e das capacitações tecnológicas que adquiriu para o resultado (passado) de suas estratégias.

Por sua vez, $\tilde{f}$ é definido tal que:

$$
\tilde{f}=\left\{\begin{array}{l}
0 \text { se } k=1 \\
0 \text { se }\left((t-1)-\sum_{k=2}^{t-1} \tilde{d}_{i, t-k}\right)<\left[\Phi_{i, \Delta t(k)}\right] \\
\left((t-1)-\sum_{k=2}^{t-1} \tilde{d}_{i, t-k}\right)-\left[\Phi_{i, \Delta t(k)}\right] \text { c.c. }
\end{array}\right.
$$

onde $\left[\Phi_{i, \Delta t(k)}\right]$ é o menor inteiro na vizinhança de $\Phi_{i, \Delta t(k)}$, definido tal que 


$$
\Phi_{i, \Delta t(k)}=u_{i}^{F}[(t-1)-(t-k)]=u_{i}^{F}(k-1)
$$

é o nível de aspiração que a firma possui, dado por suas "expectativas tecnológicas", quanto aos fracassos relativos que julga aceitável incorrer entre o período $t-1$ e $t-k$; a fim de tornar específico à firma o percentual $u_{i}^{F}$ que determina esse nível de aspiração satisfatório, podemos defini-lo de modo que

$$
u_{i}^{F} \sim U\left[p^{\min }, q^{\max }\right] \forall i=1, \ldots, n
$$

onde $0<p^{\min }<q^{\max }<1$, sendo $p^{\min }, q^{\max }$ parâmetros.

Observe-se que a equação em (8) implica, de modo análogo à parte tácita do conhecimento, que o "fluxo" mais recentemente incorporado $(t-1)$ à base de conhecimento da firma não sofre, no período $t$, qualquer tipo de "depreciação", seja porque é possível que a firma ainda não conheça o resultado de sua estratégia tecnológica no (início do) período corrente, seja porque suas rotinas organizacionais indicam que o resultado de um único período (se fracasso, isto é, se $\tilde{d}_{i, t-1}=0$ ) é ainda insuficiente para justificar qualquer rearticulação dos elementos da base de conhecimento. Em todo caso, para $k>1$ a variável $\tilde{f}$ indica o número de "fracassos" obtidos pela firma, para além do que julgaria satisfatório, entre o período passado e o período em que certa "parte" da base de conhecimento foi incorporada.

Observe-se que $\tilde{d}_{i, t}$ é uma variável aleatória de Bernoulli cujo resultado é tal que,

$$
\tilde{d}_{i, t}=\left\{\begin{array}{l}
1 \text { com probabilidade } F_{\Gamma}\left(\Gamma_{i, t} b \theta_{i, t}\right) \\
0 \text { com probabilidade } 1-F_{\Gamma}\left(\Gamma_{i, t} b \theta_{i, t}\right)
\end{array}\right.
$$

por ora bastando notar que $F_{\Gamma}: \mathbb{R}^{+} \rightarrow[0,1]$ é a função de distribuição de probabilidade que indicará o resultado (sucesso ou fracasso) da estratégia tecnológica (inovação ou imitação) da firma $i$ no período $t$, sendo seu resultado dependente (i) da base de conhecimento tecnológica da firma no período, $\Gamma_{i, t}$, definida na equação (1), (ii) de um parâmetro $b$ que depende se a firma é inovadora $\left(b=b^{n}\right)$ ou imitadora $\left(b=b^{m}\right)$, e (iii) da competência tecnológica da firma no período corrente, $\theta_{i, t}$, que será definida em seguida. 
Corolário 2: A taxa de "depreciação" da parte codificada dos vários "módulos" que fazem parte da base de conhecimento da firma $i$ no período $t-k, 1-\rho_{i, t-k}^{C}$, possui duas propriedades. Primeiro, que a "depreciação" será maior quanto mais a firma, dentro do intervalo de tempo relevante $(t-k, t-2 ; \forall k>2$ onde $k=$ $1, \ldots, t-1)$, tenha fracassado em suas estratégias tecnológicas, tendo obtido resultados insatisfatórios acima daquilo que julgaria adequado. Segundo, que os efeitos desses resultados sobre a intensidade da "depreciação" são relativamente menores à medida que aumentam.

Prova: O corolário acima é inferido trivialmente do fato que, em (8), fazendo $h=\left(\frac{1}{(1+\alpha)}\right)$, temos que

$$
\frac{\partial\left(1-h^{\tilde{f}}\right)}{\partial \tilde{f}}=-h^{\tilde{f}} \ln h=-\left(\frac{1}{1+\alpha}\right)^{\tilde{f}} \ln \left(\frac{1}{1+\alpha}\right)
$$

que é maior que zero para todo $\tilde{f} \geq 1$, já que $\ln \left(\frac{1}{1+\alpha}\right)<0 \forall \alpha>0$; em adição, tem-se também que

$$
\frac{\partial^{2}\left(1-h^{\tilde{f}}\right)}{\partial \tilde{f}^{2}}=h^{\tilde{f}}(\ln h)^{2}
$$

que é menor que zero $\forall \widetilde{f} \geq 1$, já que, agora, $(\ln h)^{2}>0$, uma vez que $0<h<1$. Assim, é verdade que

$$
\frac{\partial}{\partial \tilde{f}}\left(1-\rho_{i, t}^{C}\right)>0 \text { e } \frac{\partial^{2}}{\partial \tilde{f}^{2}}\left(1-\rho_{i, t}^{C}\right)<0
$$




\section{A dinâmica do processo de codificação do conhecimento tecnológico}

Há três razões para que a mudança na divisão da base de conhecimento, entre uma parte tácita e outra codificada, esteja diretamente relacionada ao grau de maturidade da tecnologia ${ }^{16}$ que a firma está explorando. Primeiro, porque à medida que a firma vai ultrapassando as fases iniciais do processo de exploração das oportunidades tecnológicas, a rotinização dos procedimentos de P\&D efetuados vai permitindo que parte do conhecimento tecnológico tácito, utilizado na solução dos problemas que surgiram, seja documentada e facilmente acessível para a própria firma. Segundo, porque o avanço da firma em direção à fronteira tecnológica vai permitindo que certas orientações se tornem mais claras, de maneira que a firma possa desenvolver e investir na codificação de seu conhecimento e capacitações tecnológicas. Terceiro, porque os recursos financeiros que a firma vai obtendo em conseqüência das vantagens competitivas que o sucesso de suas estratégias tecnológicas produz (mesmo que transitórias), permitem cobrir mais facilmente os custos do processo de codificação.

Assim, conforme indicado em (6), o grau de codificação da base de conhecimento da firma $i$ no período $t, \eta_{i, t}$, pode ser definido de tal forma que

$$
\eta_{i, t}=\eta_{\min }+\left(\frac{\bar{\pi}_{i, t}-\pi_{\min }}{\pi_{\max }-\pi_{\min }}\right)\left(\eta_{\max }-\eta_{\min }\right)
$$

onde $\eta_{\max }$ e $\eta_{\min }$ são parâmetros que definem os limites máximo e mínimo, respectivamente, de codificação da base de conhecimento, e $\bar{\pi}_{i, t}=\sum_{j=1}^{k} \beta_{i, j, t} \pi_{i, j, t}$ é a produtividade média da firma $i$ no período $t$, representada pela produtividade de cada equipamento $j$ que a firma $i$ possui em $t, \pi_{i, j, t}$, ponderada pelo percentual da capacidade produtiva da firma no período $t$ que opera com este equipamento $j$. Estamos supondo que cada firma, inicialmente, possua um mesmo nível de produtividade, dado por $\pi_{\text {min }}$, e que esse nível se modifica em razão do sucesso maior ou menor de suas estratégias tecnológicas; do mesmo modo, suporemos também a existência de uma produtividade limite ${ }^{17}$ (ou seja, uma fase de esgotamento na exploração das oportunidades inovativas; veja figura 1 em seguida).

\footnotetext{
${ }^{16}$ Malerba e Orsenigo (1997) e Balconi (2000).

${ }^{17} \mathrm{Na}$ verdade, estamos assumindo que o processo de exploração das oportunidades inovativas exibe fases distintas e é esgotável. Nesse sentido, Dosi (1988), Gort e Wall (1986), Sahal (1981) e Winter (1984).
} 
Figura 1

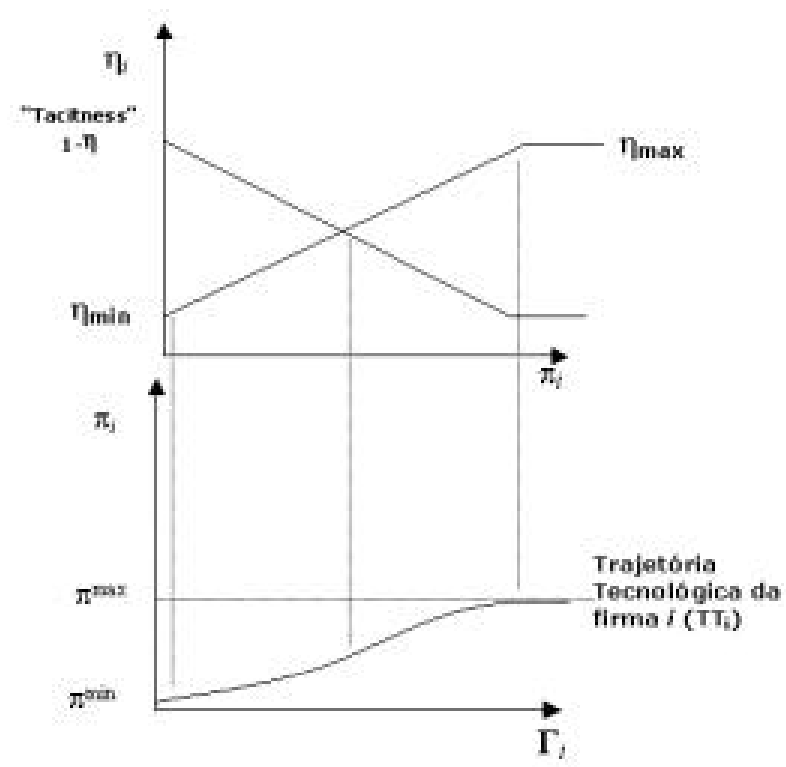

\section{Capacidade de absorção da firma e a dualidade do seu esforço de P\&D}

O engajamento da firma na atividade de P\&D possui uma dupla funcionalidade, como destacaram Tirole (1988), Cohen e Levinthal (1989), Freeman (1994), Nooteboom (1999), Llerena e Oltra (2000): produz conhecimento e capacitações tecnológicas que permitam à firma obter técnicas mais produtivas (o que, no presente modelo, pode se dar tanto por meio de inovação quanto de imitação) e cria capacitações para apreender conhecimento tecnológico das firmas rivais e até mesmo o conhecimento tecnológico e científico produzido fora da indústria. Entre os elementos que formam a base de conhecimento da firma i no período t, definidos em (1), há ainda o que se chamou de esforço tecnológico, representado pelos recursos que a firma dedica em cada período à atividade de $\mathrm{P} \& \mathrm{D}$ :

$$
E_{i, t}=\omega\left(p_{i, t-1} x_{i, t-1}\right)
$$

onde:

$\omega$ indica o percentual da receita de vendas que a firma $i$ investe em $\mathrm{P} \& \mathrm{D}$; 
$p_{i, t-1}$ é o preço praticado no período prévio; e

$x_{i, t-1}$ as vendas efetivas da firma no mesmo período. ${ }^{18} \mathrm{~A}$ capacidade de absorção da firma $i$ no período $t$ é dada por:

$$
\xi_{i, t}=\left\{\begin{array}{l}
0 \text { se } E_{i, t-1}<E^{\mathrm{min}} \\
1-\frac{1}{\hat{d} \ln \left(1+E_{i, t-1}\right.} c . c .
\end{array}\right.
$$

de maneira que $0<\xi_{i, t} \leq 1 \forall t \in T$, onde $T$ é um conjunto de índices, $\hat{d}$ é um parâmetro positivo menor que a unidade, e $E^{\text {min }}$ indica o investimento em P\&D a partir do qual a firma já se capacita a internalizar, em alguma medida, os spillovers de $\mathrm{P} \& \mathrm{D}$ intra e extra industriais.

\section{Spillovers de P\&D e a questão da "distância tecnológica"}

O processo de mudança técnica dentro das firmas resulta não apenas do acúmulo de conhecimentos gerados pela própria atividade de $\mathrm{P} \& \mathrm{D}$ da firma, mas também da internalização do conhecimento produzido pela atividade de P\&D das demais firmas na indústria (spillovers intra-industriais) e mesmo de outros agentes/instituições da economia (spillovers extra-industriais) - veja-se Cohen e Levinthal (1989), Griliches (1992) e Caniëls e Verspagen (2001). Contudo, o grau em que as firmas se beneficiam do conhecimento tecnológico de suas rivais é influenciado por aspectos que são, em última instância, específicos a cada firma (e.g. base de conhecimento tecnológico, capacidade de absorção), de modo que não há razão para supor que as firmas em uma indústria se beneficiem igualmente do conhecimento tecnológico de suas rivais; a idéia, portanto, é não apenas introduzir spillovers, mas fazê-lo superando especificações que utilizam aspectos ou hipóteses que suprimem ou são incompatíveis com a diversidade comportamental e a assimetria tecnológica existente na indústria - veja-se, por exemplo, Jaffe (1986), Griliches (1992) e Adams (2000).

Assim, definiremos o elemento $S_{i, t}$ da equação (1) como a soma de parte do esforço de $\mathrm{P} \& \mathrm{D}$ conduzido por cada uma das outras firmas na indústria no período passado, que no período $t$ está acessível para a firma $i$ :

$$
S_{i, t}=\sum_{i \neq j}^{n} \lambda_{i, j}^{t} k\left(\eta_{j, t-1}\right)
$$

\footnotetext{
${ }^{18}$ As equações que determinam as vendas da firma (depende de sua participação de mercado e da demanda total do período ao produto do setor) vêm do modelo elaborado por Possas et alii (2001), ao qual integraremos o presente modelo de busca tecnológica.
} 
onde:

$\left(\eta_{i, t} E_{j, t-1}\right)$ indica a parte codificada do esforço de $\mathrm{P} \& \mathrm{D}$ da firma $j$ no período passado que está sujeita a algum tipo de apropriação por outras firmas no setor; $K$ é um parâmetro de natureza institucional que indica o grau de apropriabilidade do esforço tecnológico das firmas no setor, sendo portanto uma espécie de taxa de spillover que denota o percentual da parcela do esforço de P\&D codificado da firma $j$ que pode ser apropriado pela firma $i$;

$\lambda_{i, j}^{t}$, por sua vez, indica a magnitude dos spillovers que a atividade de $\mathrm{P} \& \mathrm{D}$ da firma $j$ gera que está acessível para a firma $i$ no período $t$, tal que

$$
\lambda_{i, j}^{t}=h\left(\Omega_{i, j}^{t}\right)
$$

onde $\Omega_{i, j}^{t}$ representa a distância tecnológica entre a firma $i$ e a firma $j$ no período $t$ que se inicia. A medida de distância tecnológica que utilizamos não se baseia em distribuição de patentes (Jaffe, 1986) ou em proxies do grau de especialização das firmas (Peretto e Smulders, 2002), mas na relação existente entre a base conhecimento de um par arbitrário de firmas, $i$ e $j$ digamos, tal que

$$
\Omega_{i, j}^{t}=\ln \left(\frac{\Gamma_{i, t-1}}{\Gamma_{j, t-1}}\right)
$$

onde $\Gamma_{i, t-1}$ indica a base de conhecimento tecnológico da $i$-ésima firma no período passado. A fim de que a formulação em (17) capte a propriedade do benefício assimétrico referida na literatura sobre inovação e spillovers (Griliches, 1992), definiremos $h\left(\Omega_{i, j}^{t}\right)$ tal que

$$
h\left(\Omega_{i, j}^{t}\right)=\exp -\left\{v\left(\Omega_{i, j}^{t}\right)^{2}\right\}
$$

onde $h: \mathcal{R} \rightarrow(0,1]$ (sobrejetiva) e $v$ indica o grau de assimetria dos spillovers entre as duas firmas (mais adiante). Note então que $\lambda_{i, j}^{t}$ será tanto maior (menor) quanto mais tecnologicamente próximas (distantes) as firmas $i$ e $j$ sejam tal como definido em (18).

Quanto aos spillovers extra-industriais de P\&D, como este é um modelo com apenas uma indústria, o tratamento será bastante simplificado e exógeno, de forma que será possível captar apenas de forma aproximada a influência que a atividade de P\&D conduzida por instituições públicas de pesquisa (universidades, laboratórios de pesquisa financiados pelo setor público, etc.) tem na capacidade tecnológica das firmas (Freeman, 1994, Cohen e Levinthal, 1989). Assim, será definido que, 


$$
S_{t}^{P}=\zeta\left(m \sum_{i=1}^{n} S_{i, t-1} E_{i, t}\right) ; m>>1
$$

onde $m$ é um múltiplo do esforço tecnológico médio ponderado - medida aproximada do P\&D público - e $\zeta$ é o grau de "focalização" desse P\&D, ou seja, o quanto dele é "útil" para as firmas nesta indústria.

\section{A assimetria dos spillovers intra-industriais}

Diferentemente do tratamento encontrado na literatura (Griliches, 1992, Adams, 2000), os spillovers de P\&D neste modelo ocorrem nas duas direções: a firma $i$ se beneficia do gasto em $\mathrm{P} \& \mathrm{D}$ efetuado pela firma $j$ no período prévio, e vice-versa; mas os "fluxos" de conhecimento tecnológico que podem ser internalizados por uma delas (dado por $\lambda_{i, j}^{t}$ ) pode ser muito distinto do que foi internalizado pela outra. Firmas mais "avançadas" tecnologicamente se beneficiarão relativamente menos do que as que estão relativamente "atrasadas" do ponto de vista de sua base de conhecimento e capacitações tecnológicas, tal que:

$$
\left\{\begin{array}{l}
v=k_{1} \text { se } \Omega_{i, j}^{t} \geq 0 \\
v=k_{2} \text { se } c . c .
\end{array}\right.
$$

onde $k_{1}>k_{2}\left(k_{1}, k_{2} \in(0,1]\right)$.

A assimetria dos spillovers está baseada em dois aspectos. De uma lado, o fato de que as firmas diferem quanto à capacidade de absorção das externalidades de P\&D de dentro e de fora da indústria (Cohen e Levinthal, 1989). De outro, a idéia de que a firma que está "adiantada" tem potencialmente menos a ser aprendido da firma que está "atrasada".

Sobre os valores que podem ser assumidos por $\lambda_{i, j}^{t}$ (ver figura 2), vale fazer ainda duas observações:

(a) $\exists \tau>0$ arbitrariamente pequeno tal que, ainda que se tenha $\Gamma_{i, t-1}>\Gamma_{i, j-1}$, mas sendo uma desigualdade de tal ordem que faça $\Omega_{i, j}^{t}<\tau$, segue, por (18) e $\forall v \leq 1$, que $\lambda_{i, j}^{t}=1$; de modo análogo,

(b) $\exists \tau^{\prime}>0$ arbitrariamente grande tal que, para qualquer que seja a desigualdade entre $\Gamma_{i, t-1}>\Gamma_{i, j-1}$, mas se for uma desigualdade de tal ordem que faça $\left|\Omega_{i, j}^{t}\right|>\tau^{\prime}$, segue, por (19), e $\forall v \neq 1$ em (18), que $\lambda_{i, j}^{t}=0$. 
A figura abaixo dá uma indicação intuitiva das situações possíveis e da relação que existe entre $\lambda_{i, j}^{t}$ e $\Omega_{i, j}^{t}$ :

Figura 2

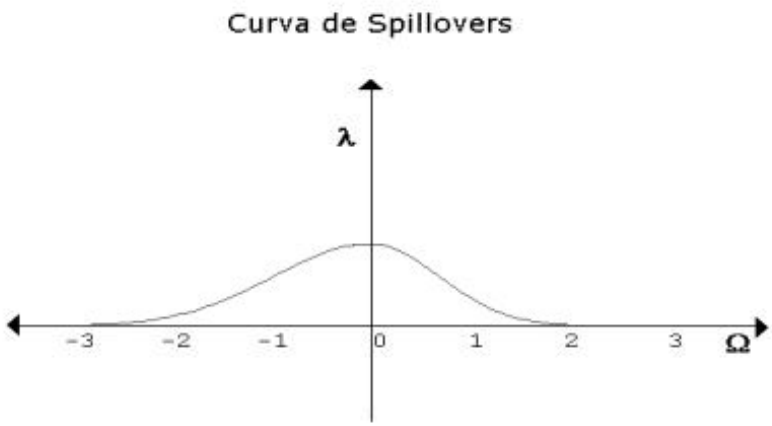

Vale observar que $\Omega_{i, j}^{t}=0$ não implica spillovers nulos, mas apenas que eles são da mesma magnitude em ambas as direções, donde se pode extrair, tendo-se em mente inclusive as observações feitas em (a) e (b), o seguinte corolário:

Corolário 3: É preciso existir algum grau de variedade tecnológica entre as firmas para que os spillovers de P\&D possam, pela forma assimétrica com que beneficiarão as firmas na indústria, ser uma fonte potencial de vantagem competitiva.

Prova: Para o caso exemplar de duas firmas apenas, $i$ e $j$, sabe-se que $S_{i, t}=$ $\lambda_{i, j}^{t}\left[k\left(\eta_{j, t} E_{j, t-1}\right)\right]$ e $S_{j, t}=\lambda_{j, i}^{t}\left[k\left(\eta_{i, t} E_{i, t-1}\right)\right]$ são os spillovers de P\&D que a firma $i$ e a firma $j$, respectivamente, podem internalizar, dependendo de sua capacidade de absorção, uma da outra, no período $t$. É fácil ver que se tais firmas são relativamente homogêneas do ponto do conhecimento e das capacitações tecnológicas que possuem, de modo que $\left|\ln \left(\Gamma_{i, t} / \Gamma_{j, t}\right)\right| \in(0, \epsilon)$, onde $\epsilon>0$ é arbitrariamente pequeno, então os spillovers líquidos, por (18) (supondo, a título de exemplo, $\left.\eta_{i, t} E_{i, t-1}=\eta_{j, t} E_{j, t-1}\right)$, serão nulos, de sorte que $S_{i, t}-S_{j, t}=0$. Assim, $\exists \epsilon^{\prime}>\epsilon$ tal que $\left|\ln \left(\Gamma_{i, t} / \Gamma_{j, t}\right)\right| \in\left(\epsilon, \epsilon^{\prime}\right)$, de maneira que $S_{i, t} \neq S_{j, t}$, seja porque $\lambda_{i, j}^{t}>\lambda_{j, i}^{t}$ ou porque $\lambda_{i, j}^{t}<\lambda_{j, i}^{t}$ - já que, se for $\left|\ln \left(\Gamma_{i, t} / \Gamma_{j, t}\right)\right|>\epsilon^{\prime}$, para um $\epsilon^{\prime}$ grande, então $\lambda_{i, j}^{t}=\lambda_{j, i}^{t}$ como já se indicou. Daí segue que existe um limite a tal "gap" tecnológico entre as firmas, para que os resultados não sejam nulos - que prevaleceria se as firmas tivessem bases de conhecimento e capacitação tecnológica muito divergentes. 


\section{Competência tecnológica: introduzindo cumulatividade tecnológica}

Como foi discutido mais detalhadamente em Almeida (2004), a especificação analítica do processo inovativo em vários modelos evolucionários não exibe qualquer tipo de cumulatividade. Além de estar em flagrante oposição com indicações presentes em textos dos próprios autores (veja, por exemplo, Dosi e Nelson (1994), Dosi (1988)), contraria aspecto empírico da atividade de P\&D, a saber, a contínua influência do esforço de P\&D passado nos potencias resultados no presente (Freeman, 1994, Malerba e Orsenigo, 1997). Eliminando a influência dos gastos realizados em P\&D ou mesmo de outra medida de desempenho histórico que sirva como proxy da eficiência com que a firma historicamente utiliza tais recursos, a formulação do processo de busca tecnológica da firma fica empírica e logicamente fragilizada ao permitir a equalização de firmas que possuem diferentes níveis de "competência" tecnológica. 19

Assim, ao introduzir cumulatividade pretendemos tornar o potencial inovativo/imitativo (doravante tecnológico apenas) de uma firma $i$ que foi relativamente mais bem sucedida em suas estratégias no passado do que a firma $j$, maior do que o potencial detido pela firma $j$, de modo que

$$
\operatorname{Pr}\left(\tilde{d}_{i, t}^{n}=1 \mid \tilde{d}_{i, t-k}^{n}=1\right)>P\left(\tilde{d}_{j, t}^{n}=1 \mid \tilde{d}_{j, t-m}^{n}=1\right) \forall k<m
$$

implicando que o potencial tecnológico da firma $i$ será tanto maior ( $\operatorname{supondo} \Gamma_{i, t}=$ $\left.\Gamma_{j, t}\right)$ quanto mais recentes forem os resultados positivos de suas estratégias vis $\grave{a}$ vis a firma $j$, que a despeito de poder também deter o mesmo número de sucessos inovativos/imitativos prévios, os obteve em períodos menos recentes.

Nesse sentido, é possível definir $I_{i, t-k}^{\tilde{d}}$ como um indicador da importância relativa do resultado da estratégia tecnológica no $(t-k)$-ésimo período (onde $k=1, \ldots, t-1), I_{i, t-k}^{\tilde{d}}$ digamos, para o sucesso da busca tecnológica no período corrente $t$, de maneira que tal indicador possua a seguinte propriedade:

$$
I_{i, t-k}^{\tilde{d}}>I_{i, t-2}^{\tilde{d}}>\ldots>I_{i, 2}^{\tilde{d}}>I_{i, 1}^{\tilde{d}}
$$

Embora essas características sejam importantes, é preciso complementá-las com outras num mecanismo que possa ampliar o potencial tecnológico das firmas

\footnotetext{
${ }^{19}$ Um exemplo ilustrativo: suponha duas firmas, A e B, operando no mercado há $k$ períodos e que em um certo período $t>k$ possuem gastos equivalentes em $\mathrm{P} \& \mathrm{D}$ - conquanto possuam "históricos" inovativos diferentes: ainda assim, a capacidade inovativa de A e B - a probabilidade de ter um sucesso inovativo - seriam equivalentes pela formulação utilizada, o que é flagrantemente irrealista. Esse problema ficaria mais evidente caso se comparasse firmas que já operam no mercado - já possuem experiência em P\&D - com firmas que entraram recentemente no mercado.
} 
além daquele que prevaleceria para uma base de conhecimento tecnológico de certa dimensão e nenhuma estratégia tecnológica bem-sucedida no passado.

Para o cômputo do que será chamado, em seguida, "competência tecnológica" das firmas na indústria, e incorporando as características da expressão em (23), vamos definir como função inversamente proporcional ao tempo, de modo que:

$$
\varphi_{i, t-k}=\frac{1}{\sqrt{k}}\left(1-\hat{i} \sum_{l=1}^{k-1} \tilde{d}_{i, t-k+1}\right) ; k=1, \ldots, t-1
$$

onde a expressão entre parênteses ${ }^{20}$ indica que o "peso" do resultado da estratégia tecnológica da firma $i$ no período $t-k$ poderá ser menor $(0<\hat{i}<1)$, além do que seria apenas pela sua posição no intervalo de tempo transcorrido, pelo fato de a firma ter obtido um número maior ou menor de sucessos subseqüentes. Há duas idéias contidas na expressão em (24). Em primeiro lugar, que os sucessos mais recentes são mais importantes para a firma e são indicadores mais robustos do domínio das fases da trajetória tecnológica que percorreu; segundo, é preciso, com base nesse critério, diferenciar a competência tecnológica de firmas que, não obstante as diferenças quanto ao período em que obtiveram sucesso, lograram o mesmo número de "sucessos" inovativos ou imitativos - de maneira a evitar o viés que existiria caso a "competência tecnológica" fosse dada apenas pelo percentual de "lances" bem-sucedidos.

É possível agora definir o histórico tecnológico da firma $i$ no período $t$ como sendo

$$
H_{t}^{i}=\sum_{k=1}^{t-1} \varphi_{i, t-k} \tilde{d}_{i, t-k}
$$

que assumirá, por exemplo, valor zero se as estratégias tecnológicas da firma $i$ não foram bem-sucedidas. A expressão em (25) pode ser vista, alternativamente, como o produto interno do $k$-ésimo vetor-linha da matriz $\mathbf{r}\left(\mathbf{v}_{k}^{i}\right.$, digamos) pelo vetor $\varphi$ (cujos elementos são dados por $(24)$ ), onde $\mathbf{r} \in \mathbf{M}\left(2^{t-1}, t-1\right)$, espaço vetorial cujas dimensões, $2^{t-1}$ e $t-1$, decorrem do fato de que, no início do $t$-ésimo período, existem $2^{t-1}$ combinações de possíveis seqüências de $t-1$ resultados (fracasso e sucesso). $\mathbf{v}_{k}^{i} \in \mathbb{R}^{t-1}$ é o vetor cujos elementos descrevem a seqüência de resultados da estratégia tecnológica da i-ésima firma.

Assim, combinando as expressões em (24) e (25), é possível definir

\footnotetext{
${ }^{20}$ Definiremos por convenção, para o caso em que $k=1$, que $\tilde{d}_{i, t}=0$.
} 


$$
\theta_{i, t}=\frac{H_{t}^{i}}{\sum_{k=1}^{n} \varphi_{i, t-k}}
$$

como sendo a "competência tecnológica" da firma $i$ no mesmo período; este seria um indicador de competência que reflete o domínio que a firma possui da trajetória tecnológica, onde $0 \neq \theta_{i, t} \neq 1$.

\section{Primeiro estágio do processo de busca tecnológica: o resultado das estratégias tecnológicas}

O processo que define o resultado das estratégias tecnológicas das firmas (inovadoras e imitadoras), segue, na forma, o tratamento existente no modelo NW (Nelson e Winter, 1982): um processo estocástico em dois estágios onde, no primeiro, se define o sucesso ou fracasso da estratégia (imitação ou inovação) e, no segundo, a produtividade que será alcançada. Num caso e noutro as equações são muito semelhantes, e, sempre que possível, nos referiremos a um caso apenas. Vale lembrar também que usaremos a base de conhecimento tecnológico normalizada ${ }^{21}$ pela capacidade produtiva da própria firma, de modo que $\hat{\Gamma}_{i, t}=\Gamma_{i, t} / \xi_{i, t}$. Assim, para o caso das firmas inovadoras e desde que $\hat{\Gamma}_{i, t} \geq 0$, segue então que

$$
\operatorname{Pr}_{\Gamma}\left(\widehat{\Gamma}_{i, t}^{*}<\widehat{\Gamma}_{i, t}\right)=F_{\Gamma}\left(\widehat{\Gamma}_{i, t}\right)=\frac{\left[\exp \left(b^{n} \widehat{\Gamma}_{i, t}\right)\left(1+\theta_{i, t}-\Lambda_{i, t}\right)\right]}{\left\{a+\left[\exp \left(b^{n} \widehat{\Gamma}_{i, t}\right)\left(1+\theta_{i, t}-\Lambda_{i, t}\right)\right]\right\}}
$$

que indica a probabilidade de a firma inovadora, cuja base de conhecimento tecnológico normalizada no período $t$ é $\widehat{\Gamma}_{i, t}$, obter um sucesso inovativo; $a$ é um parâmetro que indica o grau de dificuldade em ser bem sucedido para uma base de conhecimento relativamente pequena; $\Lambda_{i, t}=\delta^{\prime}\left(\frac{\bar{\pi}_{i, t}-\pi_{\min }}{\pi_{\max }-\pi_{\min }}\right) ; 0<\delta^{\prime}<1$, por sua vez, capta o grau de dificuldade da firma em obter sucesso inovativo quando se aproxima da fronteira tecnológica - o que é consistente com várias indicações de que o esgotamento relativo das oportunidades tecnológicas torna mais lento/difícil o progresso técnico, exigindo um acúmulo de conhecimento e de capacitações tecnológicas relativamente maior comparado com os estágios iniciais da trajetória. ${ }^{22}$

\footnotetext{
${ }^{21} \mathrm{~A}$ normalização serve para evitar que, usando apenas $\Gamma_{i, t}$, tenhamos que acrescentar novos parâmetros de ajuste em seus determinantes para evitar que assuma valores que podem produzir uma probabilidade de ter sucesso sempre unitária, ainda que a indústria esteja em sua fase inicial.

${ }^{22}$ Cf., por exemplo, Dosi $(1988,1991)$.
} 
Observe-se que para a firma que imita a expressão é a mesma, substituindo-se apenas o parâmetro $b^{n}$ por $b^{m}$, de maneira que $b^{n}>b^{m}$, donde segue que, se fizermos a firma $l$ inovadora e a firma $p$ imitadora, $F_{\widehat{\Gamma}}\left(\widetilde{\Gamma}_{l, t}\right) \geq F_{\widetilde{\Gamma}\left(\widehat{\Gamma}_{p, t}\right)} \forall \widehat{\Gamma}_{l, t}=\widehat{\Gamma}_{p, t}$, onde $\widetilde{\Gamma}$ é o valor da base de conhecimento da firma $i$ que seria necessário no período $t$ para produzir um sucesso em sua respectiva estratégia tecnológica. Mesmo que um e outro tipo de firma possam se beneficiar mutuamente do esforço tecnológico de firmas que possuem direcionamento distinto do seu, é razoável admitir que a probabilidade inicial de obter sucesso em suas respectivas estratégias é diferente em um caso e outro, sendo maior no caso das firmas inovadoras - daí a diferença nos parâmetros $b^{n}$ e $b^{m}$. Para o caso em que as firmas $i$ e $j$ guardam a mesma distância da fronteira tecnológica e compartilham do mesmo tipo de estratégia tecnológica, fica valendo a seguinte desigualdade:

$$
\operatorname{Pr}\left(\tilde{d}_{i, t}=1 \mid \widehat{\Gamma}_{i, t} \Gamma^{\prime}\right)>P\left(\tilde{d}_{j, t}=1 \mid \widehat{\Gamma}_{j, t}=\Gamma^{\prime}\right)
$$

desde que $\theta_{i, t}>\theta_{j, t}$.

Assim, de modo análogo ao que foi feito em Possas et alii (2001), o resultado (sucesso ou fracasso) é definido como uma variável aleatória discreta que assume valor 1 ou 0 conforme, agora, o seguinte processo:

$$
\tilde{d}_{i, t}=\left\{\begin{array}{l}
1 \text { se } Z \leq \frac{\exp \left(b^{n} \widehat{\Gamma}_{i, t}\left(1+\theta_{i, t}\right)\left(1+\theta_{i, t}-\Lambda_{i, t}\right)\right.}{a+\left[\exp \left(b^{n} \widehat{\Gamma}_{i, t}\left(1+\theta_{i, t}\right)\left(1+\theta_{i, t}-\Lambda_{i, t}\right)\right]\right.} \\
0 \text { c.c. }
\end{array}\right.
$$

onde $Z \sim U[1,0]$.

\section{Segundo estágio do processo de busca tecnológica: endogeneizando as trajetórias tecnológicas das firmas}

Sejam $\pi_{i, t}^{M}$ e $\pi_{i, t}^{N}$ os níveis de produtividade que a firma imitadora e a firma inovadora, respectivamente, poderão obter no período $t$, de forma que, se a firma imitadora obteve um sucesso imitativo no período corrente, então $\tilde{d}_{i, t}^{m}=1$, de modo que a produtividade da firma imitadora no período $t$ será dada por:

$$
\pi_{i, t}^{M}=\max _{i, j}\left\{\pi_{i, j, t}^{0}\right\} \forall i=1, \ldots, n
$$

onde $\pi_{i, j, t}^{0}$ é a produtividade inicial do equipamento/tecnologia $j$ da firma $i$ no período $t$.

O sucesso da firma inovadora no primeiro estágio, $\tilde{d}_{i, t}^{n}=1$, não garante que o nível de produtividade a ser obtido será necessariamente superior, pela simples 
razão de que seu resultado é também definido de forma estocástica - uma representação analítica que pretende captar a incerteza (maior) dos seus resultados. A produtividade a ser obtida pela inovação, tendo sido a firma bem-sucedida no primeiro estágio do processo de busca, é determinada por

$$
\pi_{i, t}^{N} \sim L N\left[\mu, \sigma^{2}\right]
$$

mas a média dessa distribuição não será determinada como no modelo NelsonWinter, que pressupunha não apenas um crescimento contínuo das oportunidades tecnológicas (ainda que não existisse qualquer indicação de mudança de paradigmas), mas que as firmas inovativas (e as imitadoras mais "fortes") seguiam, ainda que com alguma defasagem, ${ }^{23}$ os picos de produtividade dados pela fronteira tecnológica. Tal fronteira, sob a justificativa de um contínuo progresso científico, crescia exógena e continuamente conforme a taxa de crescimento da média da distribuição escolhida (lognormal) para especificar os resultados do segundo estágio do processo de busca das firmas que inovam; contudo, sem um processo de transição (ou exploração da produtividade potencial), essa exogeneidade se transmitia diretamente para o ritmo de crescimento da fronteira de produtividade das firmas.

Desse modo, a endogeneização das trajetórias passa pela subordinação da velocidade e direção da trajetória tecnológica que a firma segue ao conjunto de conhecimentos e capacitações tecnológicas acumulados ao longo de seu período de atividade; é a especificação da média que permitirá que o ritmo do progresso técnico das firmas seja endogeneizado, passando a depender de variáveis que são determinadas a partir do seu próprio desempenho e de suas estratégias tecnológicas.

A média da distribuição em (31) passa a ser então

$$
\mu\left(\widehat{\Gamma}_{i}, t\right)=\frac{\pi_{\max } \pi_{\min }}{\pi_{\min }+\left(\pi_{\max }-\pi_{\min }\right) \exp \left(c-\beta \widehat{\Gamma}_{i, t}\right)}
$$

observando que

$$
\mu\left(\widehat{\Gamma}_{i, t}, t\right)=\pi_{\min } \forall \widehat{\Gamma}_{i, t} \leq 0 \text { e } \lim _{\Gamma_{i, t} \rightarrow+\infty} \mu\left(\widehat{\Gamma}_{i, t}, t\right)=\pi_{\max }
$$

Desse modo, agora teremos que:

$$
\log \left(\pi_{i, t}^{n}\right) \sim N\left(\mu, \sigma^{2}\right)
$$

\footnotetext{
${ }^{23} \mathrm{E}$ não só porque as firmas que inovavam nem sempre obtinham sucesso em suas estratégias, mas porque, ainda que fossem bem sucedidas, nada garantiria um resultado melhor em termos de eficiência produtiva.
} 
valendo observar que o formato assumido pela trajetória tecnológica (cf. figura 1) das firmas inovadoras (logo, das imitadoras) define basicamente três fases: (1) uma fase inicial de assimilação das oportunidades (cuja "extensão" pode ser ajustada através do parâmetro $c$ ), com retornos relativamente constantes, em que o acúmulo de conhecimento e capacitações tecnológicas ainda é relativamente incipiente, (2) uma fase intermediária na qual há retornos crescentes e variações relativamente pequenas da base de conhecimento da firma podem gerar resultados significativos (ceteris paribus, o parâmetro $\beta$ permite tornar mais ou menos acentuados esses ganhos em termos de produtividade) se comparados com a fase anterior, e (3) uma fase final em que há praticamente um esgotamento das oportunidades tecnológicas e as mudanças na base de conhecimento não produzem resultados superiores àqueles já obtidos.

\section{Dinâmica Industrial em Condições de Hipercumulatividade Tec- nológica: Simulações do Modelo PK Revisitado}

Nesta seção trataremos de analisar comparativamente os resultados dos exercícios de simulação do modelo evolucionário de dinâmica industrial proposto por Possas et alii (2001) sob dois regimes tecnológicos distintos.

No regime tecnológico "science-based", o processo de busca tecnológica do modelo PK segue a formalização do modelo Nelson-Winter, no qual a fronteira tecnológica (ou, segundo os autores, a "produtividade latente") cresce $1 \%$ por período de produção; ou seja, a média da distribuição lognormal que indicará a produtividade que a firma inovativa bem-sucedida poderá obter cresce $1 \%$ a cada período. ${ }^{24}$ Na versão do PK cujo processo de busca segue o modelo desenvolvido ao longo da seção anterior, observaremos o caso do regime tecnológico que chamaremos hipercumulativo, já que combina a cumulatividade que deriva dos "market feedbacks" com a cumulatividade tecnológica. Trata-se, a rigor, de um regime no qual a fronteira tecnológica, em termos de produtividade, é fixa e distante da posição inicial das firmas, mas a trajetória que as firmas percorrem explorando as oportunidades existentes, e visando a alcançar o potencial produtivo que a fronteira tecnológica representa, é endogenamente determinada por sua base de conhecimento.

\footnotetext{
${ }^{24}$ Vale lembrar que, como $\mu_{t}^{\pi}=\pi_{0}(1+v t)$ e $\lim _{n \rightarrow N}\left\{\operatorname{Pr}\left(\mu_{t}^{\pi}-n \sigma<\pi_{i, t}^{N}<\mu_{t}^{\pi}+n \sigma\right)\right\}=1$ para um $N$ positivo não muito grande (sabe-se que para $n=2, \operatorname{Pr}(.) \approx 0.95$ ), para um valor $\sigma$ de pequeno, as firmas inovadoras bem-sucedidas no primeiro estágio do processo de busca, no período $t$, praticamente obterão a produtividade dada por $\mu_{t}^{\pi}$ - que cresce a cada período a uma taxa $v$ (assumida como 0.01).
} 


\subsection{Descrição das simulações}

Simulações são instrumentos de avaliação de modelos comumente utilizados nos casos em que soluções analíticas fechadas são impraticáveis ou mesmo impossíveis. Seus resultados permitem uma avaliação não só das implicações das hipóteses comportamentais, mas também da influência de certos aspectos modelados na forma de parâmetros sobre as trajetórias de certas variáveis. O uso das simulações permite também reproduzir e analisar cenários que, apenas com muita raridade, teriam a possibilidade de serem empiricamente observados. Embora seu uso muitas vezes apresente excessiva generalidade e careça de transparência (Nelson e Winter, 1977, Valente, 1999), essa tem sido a forma predominante de análise de modelos nessa literatura.

É verdade que a simetria com que os resultados de simulações reproduzem minimamente fatos estilizados ou propriedades de séries reais seja um critério razoável de avaliação de modelos econômicos. Conquanto esse seja o modo disseminado de avaliação de modelos em economia, sobretudo aqueles ligados à literatura de ciclo econômico (Watson, 1993), sua utilização ainda é reduzida nessa literatura que segue o chamado enfoque "neo-schumpeteriano" (uma exceção é Silverberg e Verspagen (1994)) - aparentemente, ou porque os modelos são formulados com características muito gerais, ou parte porque muitas variáveis dos modelos não possuem um correspondente empírico. Ainda assim, embora nosso propósito neste artigo seja estritamente comparativo e exploratório, é possível observar que as simulações de algumas variáveis (preço e concentração na indústria; cf. figuras 4, 6, 8, 10 abaixo) seguem trajetórias compatíveis com fatos estilizados na literatura de OI (Berry e Pakes, 2003).

As simulações que seguem ${ }^{25}$ referem-se a indústria composta de oito firmas divididas em dois grupos: quatro firmas inovadoras e quatro firmas imitadoras; a demanda da indústria cresce $1 \%$ por período. À exceção dessa orientação quanto à incorporação de tecnologia, as firmas compartilham as mesmas características iniciais. As numeradas de 1 a 4 são inovadoras e gastam $6 \%$ do faturamento em P\&D; as numeradas de 5 a 8 são imitadoras e gastam $3 \%$ em P\&D. Assume-se que cada período de produção equivale a um "trimestre", de maneira que serão feitas simulações para 100 períodos de produção ("time-steps" do modelo), ou 25 "anos" (Possas et alii, 2001). A partir da trajetória de algumas variáveis selecionadas ${ }^{26}$

\footnotetext{
${ }^{25} \mathrm{O}$ código do modelo e os exercícios de simulação foram desenvolvidos com o uso do Laboratory for Simulation Development, linguagem para simulação de modelos baseada em C++ desenvolvida por Valente (1999). Distribuições do software podem ser encontradas em http://www.business.aau.dk/ mv/Lsd/lsd.html.

${ }^{26}$ Quais sejam: (1) produtividade das firmas, (2) preços, (3) participação de mercado de cada
} 
será feita uma análise comparativa dos resultados obtidos pelo modelo PK em diferentes condições de busca tecnológica. As especificações que serão compartilhadas com o modelo PK (produção, preço e de investimento) seguem os parâmetros iniciais utilizados em Possas et al. (op. cit.). Já os parâmetros específicos do modelo apresentado estão no apêndice.

Como os resultados são preliminares e ainda muito gerais, o interesse maior das simulações será o de observar como as firmas que seguem estratégias tecnológicas distintas terão seu desempenho modificado ao longo do tempo num e noutro regime tecnológico. Em particular, nos interessará verificar como a introdução de spillovers de P\&D e de cumulatividade tecnológica podem alterar o desempenho das firmas inovadoras e imitadoras e o grau de concentração na indústria.

\subsection{Ambiente tecnológico e características estruturais da indústria representada nas simulações}

O propósito desta seção é dar uma idéia geral do tipo de indústria e de regime tecnológico aos quais se referem as simulações a seguir. A referência no primeiro caso é a taxonomia setorial elaborada por Pavitt (1984); no segundo, as dimensões básicas de um regime tecnológico como proposto por Malerba e Orsenigo (1997).

Do ponto de vista tecnológico, as características principais são:

- As oportunidades inovativas são relativamente elevadas e refletem as possibilidades de integração de conhecimentos tecnológicos externos à firma e ao próprio setor.

- O progresso tecnológico é fortemente cumulativo, tanto pelo efeito positivo que a experiência prévia das firmas desempenha no sucesso presente de suas estratégias tecnológicas, quanto pelo fato de que a base explorável de conhecimentos que utiliza é cumulativa. A combinação desses dois aspectos dá origem a um regime tecnológico que cria condições de hipercumulatividade. Vale lembrar que as vantagens associadas ao seu histórico tecnológico (maior probabilidade de obter um sucesso tecnológico no presente), na ausência de novos sucessos, tendem a se diluírem gradualmente com o passar do tempo.

- A base de conhecimento utilizada na atividade de busca tecnológica (inovação e imitação) tem um grau de codificação tanto mais elevado quanto mais bemdefinida e "madura" está a trajetória tecnológica da firma.

firma: inovadoras e imitadoras, (4) grau de concentração. 
- As condições de apropriabilidade são relativamente baixas: tanto há possibilidades significativas de imitar técnicas de firmas inovativas bem-sucedidas, quanto há difusão de parte do esforço de P\&D das firmas.

Do ponto de vista da estrutura de mercado:

- As posições competitivas das firmas são definidas basicamente a partir de seus preços - embora o atraso de entrega nas encomendas possa afetar de modo adverso sua posição relativa. Como a dinâmica dos preços depende das vantagens de custo que a obtenção de tecnologias mais eficientes pode criar, sua competitividade relativa acaba dependendo, em última instância, de suas estratégias tecnológicas.

- O setor com que opera o modelo combina elementos de setores "intensivo em escala" (scale-intensive) com elementos do "dominado pela oferta" (supplierdominated): é sempre possível destacar um ou outro elemento que, segundo a taxonomia, pertenceria a um setor diferente daqueles que reúnem, essencialmente, o maior número de elementos característicos compatíveis com o modelo proposto; daí se falar em elementos "science-based" (Possas, 1999), já que a taxa de crescimento da "produtividade latente" era explicada exclusivamente pelos avanços científicos. Mas é preciso lembrar que no setor "science-based" o investimento em busca inovativa é elevado e uma elevada proporção de suas inovações, estritamente de produtos (Pavitt, 1984), é utilizada pelo setor de bens de capital e/ou setor de bens intermediários. É um setor "intensivo em escala" pelo tipo de inovação predominante (de processos), pelas significativas economias de escala, pela integração vertical com o setor de máquinas e equipamentos que torna estratégico o desenvolvimento de uma base de conhecimento e capacitações tecnológicas, a partir de seu investimento em $\mathrm{P} \& \mathrm{D}$, para desenvolver seus próprios processos produtivos e explorar oportunidades tecnológicas; do tipo de setor "intensivo em escala" há ainda o caráter incorporado (nas máquinas e equipamentos) da mudança técnica e as economias de escala associadas à produção e à atividade de P\&D. 


\subsection{Regime tecnológico "science-based"}

\section{Produtividade}

A produtividade apresentou trajetória crescente na forma de "degraus". Nos períodos em que a produtividade permaneceu constante, as firmas não obtiveram nenhum sucesso inovativo ou imitativo, que tenderia a impulsionar a produtividade.

Figura 3

\section{Produtividade}

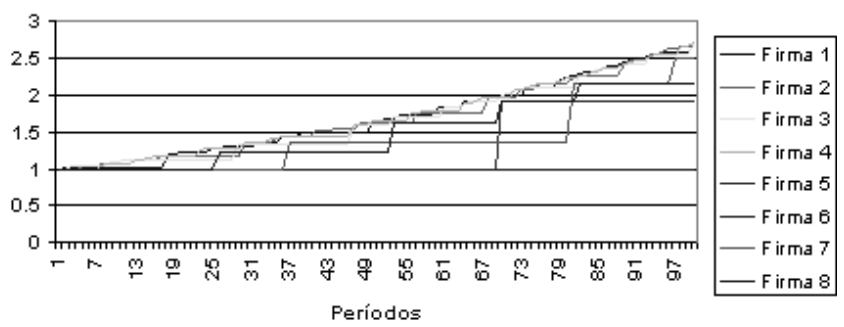

Observe-se que as firmas inovadoras seguem os deslocamentos da fronteira tecnológica com pequena defasagem, enquanto as firmas imitadoras, embora alcancem a melhor tecnologia ("best practice") existente no setor, devido ao efeito learning by doing, obtêm uma produtividade que é inferior ao nível efetivamente usufruído pelas firmas inovadoras que foram imitadas.

\section{Preços}

As simulações realizadas indicaram que os preços exibem, como esperado, trajetórias declinantes, com destaque para as trajetórias das firmas inovadoras que são relativamente mais acentuadas (figura 4). Isto decorre do fato de as inovadoras darem peso relativamente maior para seu mark-up desejado na formação de seus preços e, como possuem parcela maior do mercado, imprimem seu ritmo ao preço médio da indústria, ao qual vão se acomodando as firmas imitadoras. A convergência entre os preços vai se acentuando porque o modelo PK utiliza uma regra em que o mark-up desejado das firmas com posição no mercado relativamente pior - e esse é o caso das firmas imitadoras a partir de certo período - é igualado ao mark-up efetivo médio do último período, de maneira que sua regra 
de preço vai cada vez mais reproduzindo as condições médias vigentes no mercado, majoritariamente influenciadas pelas firma inovadoras.

Figura 4

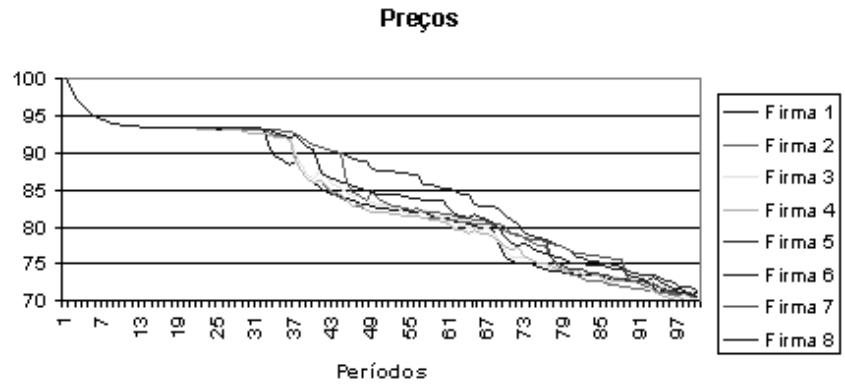

\section{Participação de mercado (market share)}

As firmas inovadoras obtiveram uma participação de mercado relativamente mais elevada, beneficiando-se de sua estratégia tecnológica. O desempenho desse grupo de firmas foi superior não apenas porque seu esforço tecnológico foi maior ${ }^{27}$ em relação ao grupo de firmas imitadoras, mas porque sua regra de preço lhes confere por hipótese uma posição de liderança (dando maior peso ao preço desejado $-70 \%$, enquanto as imitadoras atribuem $30 \%$ ), permitindo que o sucesso de suas estratégias tecnológicas (e as vantagens de custo que permite) seja explorado com maior intensidade. Isso permite, por sua vez, que suas vantagens em preços consolidem uma posição relativamente melhor no mercado obtida inicialmente. Observe-se que não há reversão significativa das trajetórias desenhadas a partir de certo período. A figura 3, que mostrou a trajetória da produtividade das firmas, deixa claro por que as imitadoras praticam estratégias de preço acomodatícias: a posição tecnológica inferior vis à vis firmas inovadoras torna mais adequado ser "seguidora" de preços do que ensaiar posições mais agressivas, sob pena de sacrificar sua posição e mesmo sobrevivência no mercado.

\footnotetext{
${ }^{27}$ Simulações com estratégias inversas (inovadoras gastando em P\&D 3\% e imitadoras $6 \%$ de sua receita), embora melhorem o desempenho das firmas imitadoras, não alteram qualitativamente os resultados em termos de participação de mercado, de maneira que seu desempenho superior está também ligado à sua estratégia de preço e às condições de financiamento (taxa de juro, aqui mantida constante); mais detalhes sobre o efeito da taxa de juros sobre o desempenho das firmas, cf. Possas et alii (2001).
} 
Figura 5

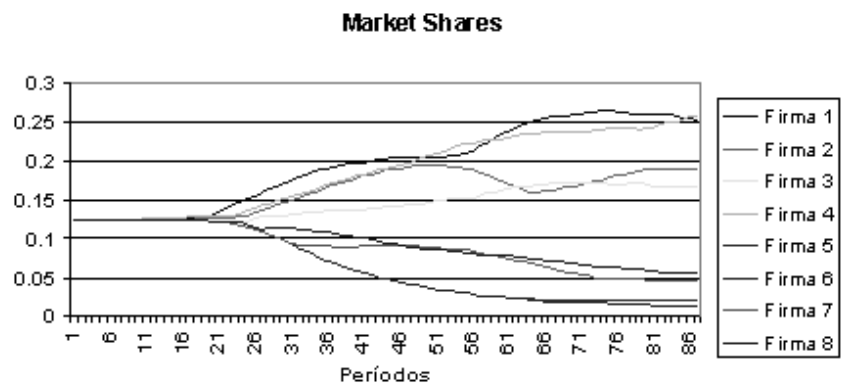

\section{Grau de concentração: HHI (índice de Hirschman- Herfindahl in- vertido $)^{28}$}

Como a taxa de crescimento da fronteira tecnológica é relativamente baixa (1\%), o grau de concentração do mercado permanece relativamente estável, como pode ser visto na figura 4 abaixo. Como foi indicado nas simulações preliminares desse modelo, o crescimento da fronteira tecnológica aumentava o grau de concentração da indústria em benefício das firmas inovadoras - já que, por definição, são as únicas capazes de, a depender dos resultados de suas estratégias tecnológicas, alcançar sistematicamente a fronteira tecnológica. O aumento dessa taxa tende a aumentar a defasagem tecnológica entre imitadoras e inovadoras e criar uma "bifurcação" nas trajetórias de ambas em termos de participação de mercado em favor das inovadoras.

Esse resultado será mais nítido quando obtivermos sua evolução em uma indústria sob um regime tecnológico distinto, que premia no presente as firmas bem-sucedidas no passado para além das vantagens que podem obter de usufruir tecnologias mais eficientes. Isso significa que as firmas que forem bem-sucedidas com maior rapidez, por um lado, poderão construir vantagens competitivas irreversíveis; mas, por outro lado, o efeito inverso resulta dos spillovers de P\&D intra-industriais, que podem chegar a reverter a trajetória de algumas firmas inicialmente em desvantagem, ainda que isso possa não implicar grandes alterações no grau de concentração do setor.

\footnotetext{
${ }^{28}$ Esse índice indica o número de firmas que possuem o mesmo tamanho que produziria um índice de Hirschman-Herfindahl de mesmo valor (Possas et alii, 2001). Quanto menor este valor, maior é a concentração da indústria.
} 
Figura 6

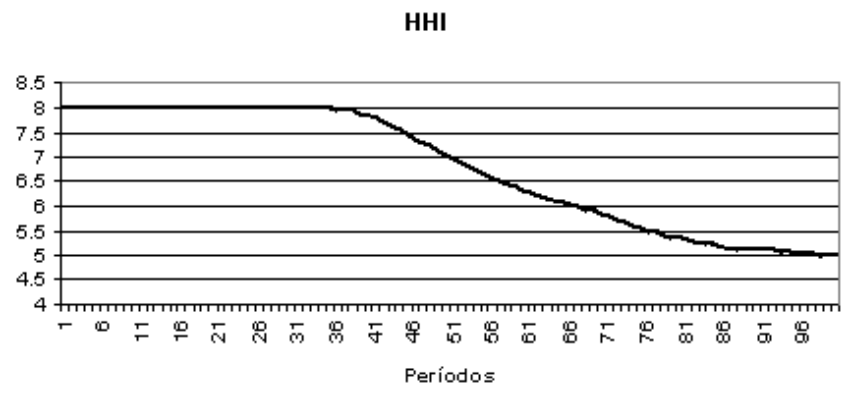

\subsection{Regime tecnológico "hipercumulativo"}

Na especificação do processo de busca tecnológica que será utilizada, as firmas mantêm as estratégias tecnológicas utilizadas nas simulações anteriores, de modo que possíveis diferenças nos resultados devem derivar fundamentalmente de dois aspectos: primeiro, da interação entre, de um lado, a realimentação de assimetrias iniciais provocadas pela cumulatividade tecnológica introduzida; e de outro, o efeito de equalização dos spillovers, tanto mais significativo quanto maior for (a) a assimetria com que as firmas podem se beneficiar umas das outras (em favor das firmas "atrasadas"), e (b) a taxa de spillovers (ou, inversamente, quanto menor for o grau de apropriabilidade do esforço de P\&D das firmas). Segundo, da forma funcional adotada para representar a trajetória tecnológica das firmas ao explorarem, gradualmente, as oportunidades tecnológicas que as conduziram para a fronteira tecnológica - com as inovadoras seguindo de modo mais aproximado do que as imitadoras, que podem alcançar a fronteira apenas indiretamente, já que estão atreladas ao desempenho daquelas em termos de produtividade.

Dado o propósito comparativo desses exercícios, os efeitos da mudança dos parâmetros ligados ao processo de "depreciação" da base de conhecimento, o grau de codificação do conhecimento e os demais parâmetros associados aos spillovers intra-industriais sobre o desempenho das firmas não serão avaliados. Observaremos apenas o tipo de relação que o desempenho das firmas guarda com seu grau de "competência tecnológica" e em que medida alterações neste podem provocar mudanças naquele. 


\section{Produtividade}

Essa é uma das variáveis cuja trajetória, como já era esperado, apresenta diferenças mais evidentes com àquela obtida no regime "science-based". O resultado decorre de dois aspectos: de um lado, o formato funcional escolhido (logístico ou sigmóide) para representar a média da distribuição da qual é extraída a produtividade das firmas inovadoras bem-sucedidas no primeiro estágio do processo de busca. O formato logístico permite que representemos fases distintas no processo de exploração das oportunidades tecnológicas.

Figura 7

\section{Produtividade}

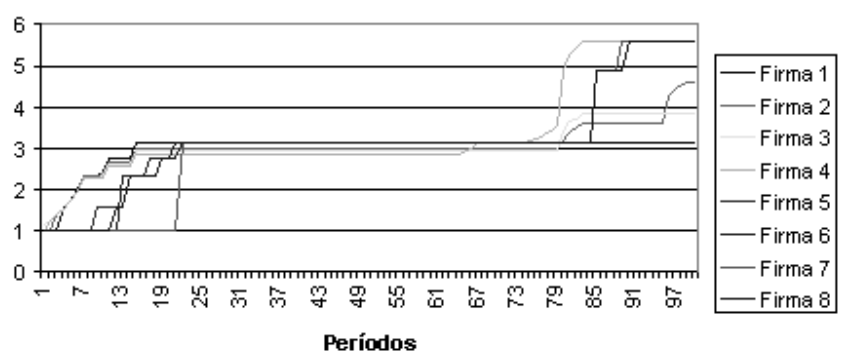

Por outro lado, como não há qualquer garantia de que a produtividade assim obtida será superior àquela que a firma obteve em período passado recente, pode ocorrer que a firma se mantenha em um nível de produtividade relativamente constante enquanto sua base de conhecimento vai crescendo (cujo efeito sobre a probabilidade de obter um sucesso é compensado pela redução da competência tecnológica); daí porque o sucesso em períodos posteriores possa provocar aumentos mais acentuados da produtividade até estabilizar-se em torno do nível dado pela fronteira tecnológica. As descontinuidades e o formato irregular são decorrências das variações de grandeza relativamente elevada (e não unitária, ou próxima disso) na base de conhecimento, que provoca saltos na produtividade média que pode ser obtida. Em outras simulações, os resultados eram menos descontínuos mas as firmas praticamente "saltavam" as fases iniciais, logo alcançado a fronteira. ${ }^{29}$

\footnotetext{
${ }^{29}$ Mais adiante, observaremos como um tratamento independente da base de conhecimento, que cresce de modo exógeno (como originalmente é feito no modelo NW, mas mantendo o formato logístico) e ainda com uma fronteira fixa, produz trajetórias mais "suaves".
} 


\section{Preços}

Figura 8

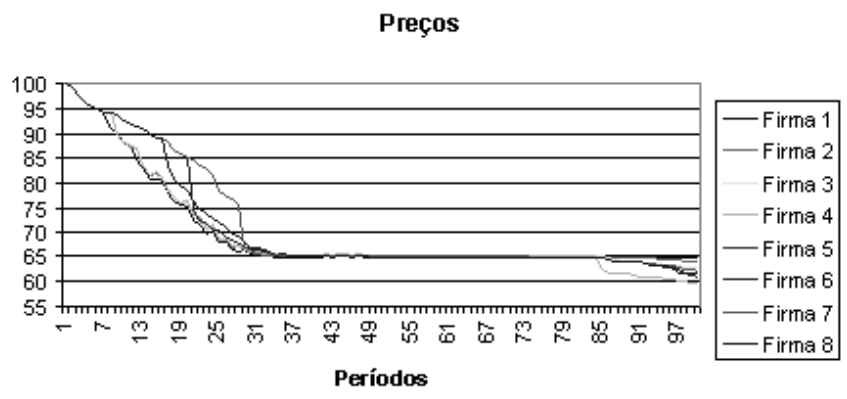

A trajetória dos preços reflete em grande medida a trajetória da produtividade das firmas, mas sua direção é praticamente uma reprodução da trajetória obtida no regime "science-based"; mais uma vez, as firmas inovadoras imprimem o ritmo de declínio nos preços. O valor final observado é ligeiramente menor do que aquele obtido anteriormente, provavelmente em razão de o nível final de produtividade alcançado ser maior. As simulações evidenciam também, como se imaginava, que a obtenção de novas tecnologias condiciona a dinâmica dos preços: embora as vantagens competitivas pareçam provir de pressões da própria rivalidade existente na indústria para adotar estratégias de preço mais agressivas (menor margem de lucro), neste padrão de concorrência elas derivam fundamentalmente do sucesso tecnológico das firmas, que pode vir a ser sancionado ou não pela demanda, dependendo da forma como as firmas distribuem as vantagens de custo decorrentes do avanço tecnológico entre preço e mark-up.

\section{Participação de mercado (market share)}

O desempenho das firmas em termos de participação de mercado (figura 9) apresenta características similares aos resultados obtidos sob o regime "sciencebased": mantém-se a dispersão inicial entre as firmas inovadoras e imitadoras e a mudança de posição é restrita ao grupo de firmas que compartilham do mesmo tipo de estratégia tecnológica (veja-se figura 5). O fato de a firma 1, a partir de certo período, reduzir sua participação de mercado está associado à velocidade com que sua trajetória tecnológica alcançou a fase de esgotamento. Observe-se que a firma 4 vai gradualmente assumindo a posição de líder porque mantém regularmente 
um elevado nível de "competência tecnológica" - ou seja, a partir de certo período foi a que mais se beneficiou do efeito da cumulatividade tecnológica (vide figura 11 abaixo). Entre as imitadoras há, até mesmo, desempenhos idênticos (caso das firmas 5 e 8); em geral, conseguem "sobreviver" ainda que em posições pouco significativas.

Figura 9

Market Shares

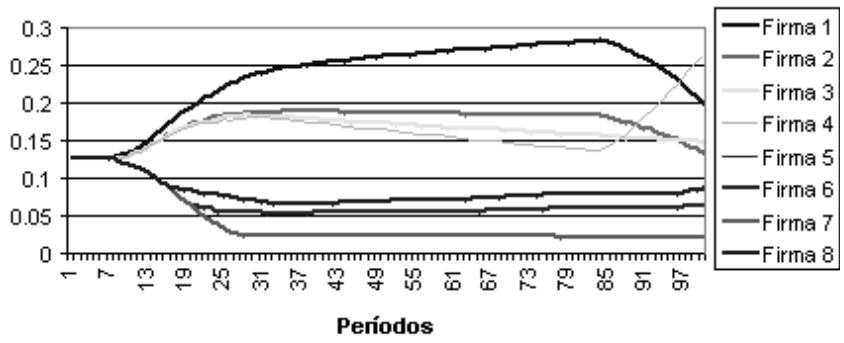

\section{Grau de concentração HHI (índice de Hirschman- Herfindahl inver- tido) $)^{30}$}

Embora o grau de concentração seja semelhante ao final das simulações, a figura 10 evidencia um processo de concentração muito mais veloz. A indústria converge mais rapidamente para um certo nível de concentração (próximo ao verificado no regime anterior) em razão dos efeitos da cumulatividade nos primeiros períodos, que acentua as assimetrias iniciais, gerando concentração em favor das firmas inovadoras, cujo dispêndio em P\&D é maior.

\footnotetext{
${ }^{30}$ Esse índice indica o número de firmas que possuem o mesmo tamanho que produziria um índice de Hirschman-Herfindahl de mesmo valor (Possas et alii, 2001). Quanto menor este valor, maior é a concentração da indústria.
} 
Figura 10

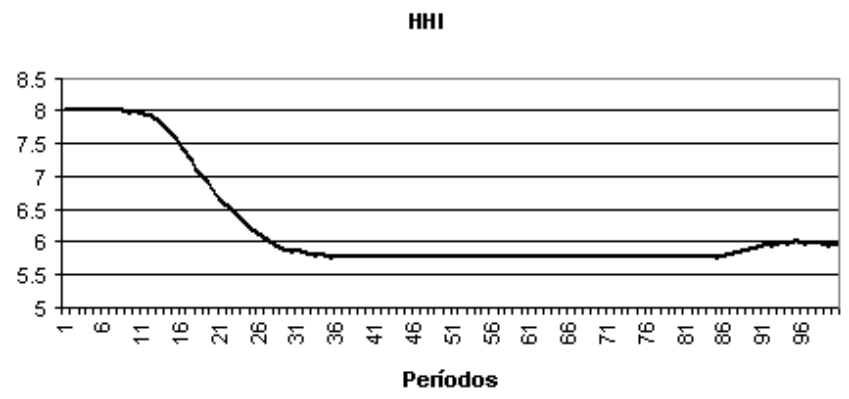

\section{"Competência tecnológica"}

Os resultados obtidos indicam, como era esperado, que o desempenho das firmas em termos de participação de mercado está correlacionado diretamente com seu nível de competência tecnológica. As firmas inovadoras exibiram maior domínio da trajetória tecnológica percorrida, mantendo níveis maiores exatamente porque o intervalo de tempo entre os sucessos consecutivos de suas estratégias tecnológicas era relativamente menor do que aquele observado entre as firmas imitadoras.

Figura 11

\section{Competência tecnológica}

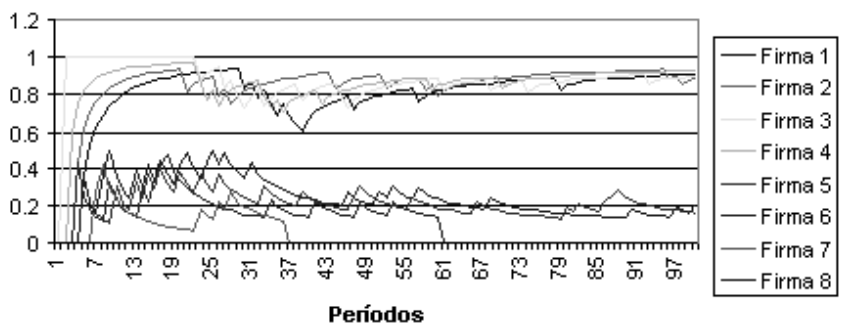




\section{Conclusões}

As principais contribuições deste artigo são essencialmente teóricas. O objetivo foi desenvolver um modelo de busca tecnológica destinado a introduzir três elementos característicos da dinâmica industrial ausentes do processo de busca do modelo Nelson-Winter reproduzidos por uma série de outros modelos evolucionários de dinâmica industrial: (1) cumulatividade tecnológica, (2) acumulação de conhecimento e capacitações tecnológicas a partir do próprio esforço de P\&D das firmas - que viria a ser a variável chave na endogeneização de suas trajetórias tecnológicas (em termos de produtividade) e (3) spillovers de P\&D (intra e extraindustriais). Além disso, o modelo desenvolvido introduziu:

- depreciação intertemporal do estoque de conhecimento tecnológico;

- separação dos efeitos que determinam a depreciação que incide sobre os tipos de conhecimento envolvidos: cognitivos no caso tácito e tecnológicos no caso codificado;

- endogeneização das trajetórias: capacitações tecnológicas determinam direção e velocidade com que as firmas percorrem as fases da trajetória tecnológica em direção à fronteira;

- regime hipercumulativo: fontes de cumulatividade introduzidas permitem análise da indústria em regimes tecnológicos distintos.

Os exercícios de simulação compararam as trajetórias das variáveis que permitem avaliar o desempenho das firmas em uma indústria e o grau de concentração nesta em dois regimes tecnológicos: "science-based", seguindo o tratamento dado no modelo NW ao processo de busca tecnológica; outra com regime tecnológico hipercumulativo, onde o processo de busca segue as formulações propostas anteriormente. Os resultados, preliminares e bastante gerais, indicam que sob o regime hipercumulativo se acentua a dispersão entre firmas inovadoras e imitadoras que existia inicialmente na indústria em regime "science-based", embora os benefícios assimétricos dos spillovers, combinados ao fato de as firmas inovadoras rapidamente atingirem a fase de esgotamento de suas trajetórias, dêem início a um processo de reversão do desempenho das firmas (em termos de participação de mercado) mas com a peculiaridade de provocar mudanças apenas entre as firmas que compartilham do mesmo tipo de estratégia tecnológica, não chegando a mudar o desempenho geral de ambos os tipos de firma. As trajetórias dos preços e do grau de concentração na indústria, embora sigam as mesmas tendências observadas no 
regime "science-based", mostraram velocidades distintas: no caso dos preços, a continuidade de sua redução estava condicionada ao crescimento mais ou menos contínuo da produtividade; no caso da concentração do mercado, embora os resultados obtidos ao fim de 100 períodos sejam próximos, no regime hipercumulativo ocorreu uma rápida concentração da indústria mesmo tendo todas as firmas "sobrevivendo" ao longo dos períodos. A razão disto parece estar vinculada ao efeito da cumulatividade tecnológica sobre o desempenho inicial das firmas: as vantagens obtidas inicialmente foram continuamente reforçadas ao menos enquanto existiam oportunidades tecnológicas a serem exploradas. O esgotamento das oportunidades tecnológicas permitiu que outras firmas obtivessem vantagens enquanto as firmas líderes (todas inovadoras) haviam esgotado suas possibilidades de obter avanços tecnológicos. Em ambos os ambientes tecnológicos, por assim dizer, as estratégias foram eficazes em garantir sobrevivência das firmas embora com um desempenho sensivelmente inferior para as imitadoras no regime hipercumulativo.

\section{Referências}

Adams, J. (2000). Endogenous r\&d spillovers and industrial research productivity. NBER Working Papers, n. 7484.

Aghion, P., Harris, C., Howitt, P., \& Vickers, J. (1991). Competition, imitation and growth with step-by-step innovation. Review of Economic Studies, 68(3):467-492.

Aghion, P. \& Howitt, P. (1992). A model of growth through creative destruction. Econometrica, 60(2):323-351.

Almeida, S. (2004). Dinâmica industiral e cumulatividade tecnológica. $26^{\circ}$ Prêmio BNDES de Economia (Dissertação de mestrado). Rio de Janeiro.

Antonelli, C. (2002). Economics of knowledge and the governance of commons knowledge. Revista Brasileira de Inovação, 1(1):29-48.

Axelrod, R. (1984). The Evolution of Cooperation. Basic Books, New York.

Baddeley, A. (1990). Human Memory: Theory and Practice. Allyn \& Bacon, Needham Heights, MA.

Balconi, M. (2000). Codification of technological knowledge, firm boundaries and cognitive 'barriers' to entry. DYNACOM Working Paper. 
Berry, S. \& Pakes, A. (2003). Introduction and stylized facts from empirical models of firms and markets. mimeo.

Caniëls, M. C. J. \& Verspagen, B. (2001). Barriers to knowledge spillovers and regional convergence in a evolutionary model. Journal of Evolutionary Economics, 11(3):307-329.

Chiaromonte, F. \& Dosi, G. (1993). The microfoundations of competitiveness and their macroeconomic implications. In Foray, D. \& Freeman, C., editors, Technology and the Wealth of Nations: The Dynamics of Constructed Advantages. Pinter Publishers, London.

Cohen, W. M. \& Levinthal, D. A. (1989). Innovation and learning: The two faces of r\&d. The Economic Journal, 99:569-596.

Dosi, G. (1988). Sources, procedures and microeconomics effects of innovation. Journal of Economic Literature, 26.

Dosi, G. (1991). The research on innovation diffusion: An assessment. In Dosi, G., editor, Innovation, Organization and Economic Dynamics, pages 115-143. Edward Elgar, London.

Dosi, G. (1996). The contribution of economic theory to the understanding of a knowledge-based economy. In OECD, editor, Employment and Growth in the Knowledge-Based Economy. Paris.

Dosi, G. \& Coriat, B. (2002). Problem-solving and coordination-govrenance: Advances in a competence-based perspective on the theory of the firm. Revista Brasileira de Inovacao, 1(1):49-84.

Dosi, G. \& Nelson, R. (1994). An introduction to evolutionary theories in economics. Journal of Evolutionary Economics, 4:153-172.

Eliasson, G. \& Day, R. D. (1986). The Dynamics of Market Economies. NorthHolland, Amsterdam.

Ericson, R. E. \& Pakes, A. (1995). Markov-perfect industry dynamics: A framework for empirical work. Review of Economic Studies, 62:53-82.

Freeman, C. (1994). The economics of technical change. Cambridge Journal of Economics, 18:463-514. 
Gort, M. \& Wall, R. A. (1986). The evolution of technologies and investment in innovation. The Economic Journal, 96:741-757.

Griliches, Z. (1992). The search for r\&d spillovers. Scandinavian Journal of Economics, 94:29-48.

Grimaldi, R. \& Torrisi, S. (2001). Codified-tacit and general-specific knowledge in the division of labour among firms: A case study of the software industry. Research Policy.

Grossman, G. M. \& Helpman, E. (1994). Endogenous innovation in the theory of growth. Journal of Economic Perspectives, 8(1):23-44.

Hopenhayn, H. (1992). Entry, exit, and firm dynamics in long run equilibrium. Econometrica, 60(5):1127-50.

Jaffe, A. B. (1986). Technological opportunity and spillovers of r\&d: Evidence from firm's patents, profits, and market value. American Economic Review, 76:984-1001.

Jonard, N. \& Yildizoglu, M. (1998). Technological diversity in an evolutionary industry model with localized learning and network externalities. Structural Change and Economic Dynamics, 9(1):33-55.

Jovanovic, B. (1982). Selection and the evolution of industry. Econometrica, $50(3): 649-70$.

Kaniovski, Y. (1998). Interdependent search and industry dynamics: On ericson and pakes (1995). International Institute for Applied Systems Analysis. Interim Report, n. 031.

Kay, N. (1988). The \&D function: Corporate strategy and structure. In Dosi, G. e. a., editor, Technical Change and Economic Theory. Pinter Publishers, London.

Kwasnicki, W. (1996). Innovation regimes, entry and market structure. Journal of Evolutionary Economics, 6(4):375-409.

Llerena, P. \& Oltra, V. (2000). Diversity of innovative strategy as a source of technological performance. DRUID Working Paper n. 00-1.

Logan, G. D. (1988). Toward an instance theory of automatization. Psychological Review, 95(4):492-527. 
Malerba, F. \& Orsenigo, L. (1997). Technological regimes and sectoral patterns of innovative activities. Industrial and Corporate Change, 6(1):83-117.

Maynard-Smith, J. (1982). Evolution and the Theory of Games. Cambridge University Press, Cambridge.

McKelvey, M. (1998). Evolutionary innovations: Learning, entrepreneurship and the dynamics of the firm. Journal of Evolutionary Economics, 8(2):157-175.

Nelson, R. (1995). Recent evolutionary theorizing about economic change. Journal of Economic Literature, 33(1):48-90.

Nelson, R. \& Winter, S. (1975). Growth theory from an evolutionary perspective: The differential productivity puzzle. American Economic Review, 65(2):338-44.

Nelson, R. \& Winter, S. (1977). Simulation of schumpeterian competition. American Economic Review, 67(1):271-76.

Nelson, R. \& Winter, S. (1982). An Evolutionary Theory of Economic Change. Belknap Press, Cambridge.

Nelson, R., Winter, S., \& Schuette, H. L. (1976). Technical change in an evolutionary model. The Quarterly Journal of Economics, MIT Press, 90(1):90-118.

Nooteboom, B. (1999). Innovation, learning and industrial organization. Cambridge Journal of Economics, 23(2):127-150.

Oltra, V. \& Yildizoglu, M. (1998). Learning and expectations in r\&d decisions. Working Papers Beta-theme (UMR n. 7522 - CNRS), PEGE, Universite Louis Pasteur, Strasbourg.

Pavitt, K. (1984). Sectoral patterns of technical change: Towards a taxonomy and a theory. Research Policy, 13.

Peretto, P. \& Smulders, S. (2002). Technological distance, growth and scale effects. The Economic Journal, 112:603-624.

Possas, M. L. (1999). Antecedentes e perspectivas teóricas da economia do desenvolvimento numa abordagem evolucionária. Revista Nexos Econômicos, $C M E / U F B a, 1(1)$.

Possas, M. L., Koblitz, A. C. V., Licha, A. L., Oreiro, J. L., \& Dweck, E. (2001). Um modelo evolucionário setorial. Revista Brasileira de Economia, 55(3):333377. 
Romer, P. M. (1994). The origins of endogenous growth. Journal of Economic Perspectives, 8(Winter):3-22.

Sahal, D. (1981). Patterns of Technological Innovation. Addison-Wesley, Massachusetts.

Silverberg, G., Dosi, G., \& Orsenigo, L. (1988). Innovation, diversity and diffusion: A self-organization model. The Economic Journal, 98(393):1032-1054.

Silverberg, G. \& Verspagen, B. (1994). Learning, innovation and economic growth: A long-run model of industrial dynamics. Industrial and Corporate Change, $3(1): 199-223$.

Simon, H. A. (1979). From substantive to procedural rationality. In Hahn, F. \& Hollis, M., editors, Philosophy and Economic Theory. Oxford University Press.

Sternberg, R. (1996). Cognitive Psychology. Cambridge University Press, New York.

Tirole, J. (1988). The Theory of Industrial Organization. MIT Press, Cambridge.

Underwood, B. J. (1957). Interference and forgetting. Psychological Review, 64:4960.

Valente, M. (1999). Evolutionary economics and computer simulations - a model for the evolution of markets. Dinamarca: Allborg University, Department of Business Studies (Tese de Doutorado).

Watson, M. (1993). Measures of fit for calibrated models. Journal of Political Economy, 101(6):1011-1041.

Winter, S. (1984). Schumpeterian competition in alternative technological regimes. Journal of Economic Behavior and Organization, 5:287-320.

Winter, S., Dosi, G., \& Kaniovski, G. Y. M. (2000). Modeling industrial dynamics with innovative entrants. Structural Change and Economic Dynamics, 11:255293.

Zack, M. H. (1999). Knowledge and Strategy. Butterworth-Heinemann, Boston. 


\section{Apêndice}

Condições Iniciais e Valores dos Parâmetros

\begin{tabular}{cccccc}
\hline $\mathrm{N}^{o}$ & Variável & Valor & $\mathrm{N}^{o}$ & Variável & Valor \\
\hline 1 & $\Gamma_{i, t}$ & 0 & 15 & $i$ & 0.2 \\
2 & $\tilde{\Gamma}_{i, t}$ & 0 & 16 & $\alpha$ & 0.2 \\
3 & $E_{i, t}$ & 0 & 17 & $u_{i}^{F}$ & $\sim \mathrm{U}\{0.5,0.8\}$ \\
4 & $\zeta_{i, t}$ & 0 & 18 & $\eta_{\min }$ & 0.2 \\
5 & $S_{i, t}$ & 0 & 19 & $\eta_{\max }$ & 0.8 \\
6 & $S_{i, t}^{P}$ & 0 & 20 & $\pi_{\min }$ & 1 \\
7 & $\theta_{i, t}$ & 0 & 21 & $\pi_{\max }$ & 5 \\
8 & $\sigma$ & 0.1 & 22 & $b^{n}$ & 0.4 \\
9 & $K$ & 0.1 & 23 & $b^{m}$ & 0.3 \\
10 & $=v(\Omega \geq 0)$ & 3 & 24 & $a$ & 3 \\
11 & $=v(\Omega<0)$ & 0.3 & 25 & $E_{\min }$ & 6.8 \\
12 & $\zeta$ & 0.01 & 26 & $\beta$ & 0.2 \\
13 & $m$ & 4 & & & \\
14 & $\sigma$ & 0.4 & & & \\
\hline
\end{tabular}

